\title{
Cone penetration testing to assess slope stability in the 1979 Nice landslide area (Ligurian Margin, SE France)
}

\author{
Steiner Albert ${ }^{1}$, Kopf Achim ${ }^{1,{ }^{*}}$, Henry Pierre ${ }^{2}$, Stegmann Sylvia ${ }^{1}$, Apprioual Ronan ${ }^{3}$, Pelleau Pascal ${ }^{3}$ \\ ${ }^{1}$ Marine Geotechnics, MARUM - Centre for Marine Environmental Sciences and Faculty of \\ Geosciences, University of Bremen, Bremen, Germany \\ ${ }^{2}$ CEREGE - Université Aix-Marseille III, Collège de France, Aix en Provence, France \\ ${ }^{3}$ Ifremer - French Research Institute for Exploration of the Sea, Centre de Brest, Plouzane, France \\ * Corresponding author : Achim Kopf, email address : akopf@marum.de
}

\begin{abstract}
:
In the landslide-prone area near the Nice international airport, southeastern France, an interdisciplinary approach is applied to develop realistic lithological/geometrical profiles and geotechnical/strength subseafloor models. Such models are indispensable for slope stability assessments using limit equilibrium or finite element methods. Regression analyses, based on the undrained shear strength (su) of intact gassy sediments are used to generate a sub-seafloor strength model based on 37 short dynamic and eight long static piezocone penetration tests, and laboratory experiments on one Calypso piston and 10 gravity cores. Significant strength variations were detected when comparing measurements from the shelf and the shelf break, with a significant drop in su to $5.5 \mathrm{kPa}$ being interpreted as a weak zone at a depth between 6.5 and $8.5 \mathrm{~m}$ below seafloor (mbsf). Here, a 10\% reduction of the in situ total unit weight compared to the surrounding sediments is found to coincide with coarse-grained layers that turn into a weak zone and detachment plane for former and present-day gravitational, retrogressive slide events, as seen in 2D chirp profiles. The combination of high-resolution chirp profiles and comprehensive geotechnical information allows us to compute enhanced 2D finite element slope stability analysis with undrained sediment response compared to previous 2D numerical and 3D limit equilibrium assessments. Those models suggest that significant portions (detachment planes at $20 \mathrm{~m}$ or even $55 \mathrm{mbsf}$ ) of the Quaternary delta and slope apron deposits may be mobilized. Given that factors of safety are equal or less than 1 when further considering the effect of free gas, a high risk for a landslide event of considerable size off Nice international airport is identified.
\end{abstract}




\section{Highlights}

- An interdisciplinary approach is used comprisntaining morphological, 2D chirp seismic, sedimentological, geotechnical laboratory and in situ datasets. Dynamic piezocone penetration tests (CPTU) provide a powerful, time- and cost-efficient in situ technique. A large number of coring, staticand mainly dynamic-CPTU tests are used to develop an area-widea regional sub-seafloor strength model near the Nice airport (southeastern France). D Detailed 2D finite element slope stability assessments are performed, according to which a. A potentially tsunamigenic submarine landslide event with a failure depth of $>$ up to 1050 m could may occur.

Keywords: Dynamic penetrometer, sub-seafloor modeling, weak zone, free gas, numerical slope stability 


\section{Introduction}

Cone penetration testing with pore pressure recording (CPTU) is a powerful, widely used, cost- and time-efficient in situ technique for sub-seafloor geotechnical investigations (Baligh et al. 1981, Lunne et al. 1997, Meunier et al. 2004, Stoll et al. 2007, Robertson 2009, Steiner et al. 2012). In the marine environment, both dynamic- and static-CPTU devices are used, but given the different modes of penetration and measure their effect on geotechnical properties make the former less common than the latter. The momentum of the dynamic-CPTU device controls the achievable penetration depth with a non-linear penetration rate up to $10 \mathrm{~m} / \mathrm{s}$, and the static-CPTU instrument penetrates the sediment with constant penetration rate of $2 \mathrm{~cm} / \mathrm{s}$. The measured dynamic-CPTU properties are generally higher than static-CPTU parameters, which is know as strain-rate effect. It is corrected using the modified inverse sin-hyperbolic equation and associated soil-specific rate coefficients (SSCs) (Randolph and Hope 2004, Steiner et al. 2014).

Given that the dynamic-CPTU device can be operated fast, a large number of in situ profiles can be collected to improve spatial coverage for sub-seafloor modeling. In turn, static devices such as the Penfeld penetrometer (Meunier et al. 2000) reach sub-seafloor levels of $>30$ mbsf and hence provide crucial information for deep-rooted detachment planes. During several field campaigns and scientific cruises from 2007 until 2012, a large number of in situ tests were performed in the vicinity of the Nice international airport, southeastern France. There, a large submarine landslide that caused significant material damage and claimed several human lives occurred on 16 October 1979 (Gennesseaux et al. 1980, Seed et al. 1988). This tsunamigenic landslide event occurred on the shelf and shelf break off the airport and mobilized approximately 9 million $\mathrm{m}^{3}$ marine clayey to silty sediments as well as engineering fill of the airport/harbor 
enlargement, which was under construction at that time (Assier-Rzadkiewicz et al. 2000).

Based on 2D numerical slope stability assessments using bathymetry maps before and after the 1979 landslide, a long onshore static-CPTU test, a short gravity core (gc) and a long Calypso piston core (срc) in conjunction with one-dimensional compression tests, Dan et al. (2007) reconstructed a coincidence of three pre-conditioning factors and triggering mechanisms leading to the 1979 landslide failure. These were: (i) coarsegrained layers and fresh water infiltration causing the origin of weak zones as a result of leaching and the increase of slow deformation processes, (ii) sudden overloading of the sediments induced by anthropogenic fill operations and embankment construction resulting in a decrease of the intact undrained shear strength $\left(s_{u}\right)$, and (iii) heavy rainfall several days before the landslide resulting in excess pore pressure $(\Delta \mathrm{u})$ and a decrease of the effective overburden stresses. Moreover, existing weak zones affected by slow deformation processes were quantified by a factor of safety (FoS) close to unity, and were interpreted as a main cause for the 1979 landslide (Dan et al. 2007). In order to evaluate the present-day stability of the Nice area, and in particular the eastern plateau near the airport, nine $28 \mathrm{~m}$ long offshore static-CPTU tests were used to perform 3D probabilistic slope stability assessments (Leynaud and Sultan 2010). These assessments predict a 5\% likelihood that a large landslide (i.e. failure plane at $60 \mathrm{~m}$ depth) will occur, but a $50 \%$ likelihood that medium landslide (i.e. failure plane at $30 \mathrm{~m}$ depth) will occur in the near future. The comparison of offshore static-CPTU tests with vane shear experiments on cored specimens as well as internal core deformation indicate the presence of free gas in the sediments (Sultan et al. 2010). Previous studies revealed subhydrostatic pore pressures and a 20 to $30 \%$ decrease of undrained shear strength in gassy sediments compared to undisturbed material (e.g. Nageswaran 1983, Seifert et al. 2008, Sultan et al. 2010). This decrease in shear strength is related to the compressibility of the gas, structural differences according to the gas concentration (i.e. 
changes in the void ratio) and increase of the pore pressure during gas accumulation (Nageswaran 1983). However, the impact on the stability of the Nice continental shelf and upper slope has not been analyzed yet.

Thus, our manuscript presents an interdisciplinary approach that tries to integrate all available data including multi-beam swath bathymetry, 2D seismic chirp profiles, coring and in situ data collected off the Nice international airport. Cores and in situ profiles are used to analyze variations of $s_{u}$ and $s_{u}$ gradients with depth in order to detect weak zones, gas-affected horizons, and other discontinuities. 2D seismic chirp transects are used to map silty to sandy layers and a weak zone in the shallow sub-seafloor $(<10$ mbsf) including correlations with morphological scars and morphological steps in the bathymetry. Finally, an area-wide geotechnical/strength model is developed using regression analyses based on the shear strength $\left(s_{u}\right)$ derived from gravity cores, static and dynamic in situ measurements. This interdisciplinary approach is then used in 2D finite element analyses that consider the effect of free gas with undrained sediment behavior in order to evaluate the overall risk as well as the volume of the potential landslide mass. Finally, implications for geohazard and landslide research in the vicinity of the Nice international airport are discussed.

\section{Geological setting}

\subsection{Geological evolution}

The French part of the Ligurian margin contains a narrow continental shelf and a steep slope off Nice and is located in the northwestern Mediterranean Sea (Figs. 1a, 1b). The region is characterized by complex tectonic processes owing to the collision of the African and Eurasian plates in the Cretaceous and early Tertiary time, including the closure of the Tethyan ocean and orogeny of the Alps (McKenzie 1970, Hsü 1971). The 
origin of the Ligurian basin is rifting and seafloor stretching during the orogenesis of the western Alps in the late Oligocene-Miocene (Le Pichon et al. 1971, Cherchi and Montadert 1982, Rehault et al. 1984). Some of the tectonic deformation in the Western Alps resulted in presently still seismically active features such as the Peille-Laghet fault in the Maritime Alps (Courboulex et al. 2007) or the Marcel fault (Fei et al. 2014). The southwestward trace of the Peille-Laghet fault turns into the "Blausasc fault" (sensu Courboulex et al. 2007) and affects the area south of the city of Nice. The nearly E-Wtrending Marcel fault is located further downslope at the Nice margin, but may equally affect slope stability in the Var canyon and adjacent slopes (Fei et al. 2014). Traces of both faults are shown in Figure $1 \mathrm{~b}$ and will be discussed in section 6.3 .

The basement of this margin is covered by $5-7 \mathrm{~km}$ of Miocene to late NeogeneQuaternary sediments consisting of conglomerates (the so-called "puddingstones", mud and marly ooze affected by frequent erosional events (Fahlquist and Hersey 1969, Auzende 1971, Le Borgne et al. 1971, Auffret at al. 1982, Savoye and Piper 1991). Dubar and Anthony (1995) and Anthony and Julian (1997) carried out detailed sedimentary analyses including three representative stratigraphical sections of the Var, Paillon and Brague river mouths (Fig. 1c). These sections mainly consist of a four-layer sedimentological/stratigraphic sequence (Fig. 2a, see also Guglielmi 1993, Dubar and Anthony 1995, Anthony and Julian 1997, Anthony and Julian 1999 for further details). In 2007, the Var section was extended by a seismic reflection transect (see Fig. 1c for location) illuminating the stratigraphic sequence for the Nice continental shelf and upper slope, and potentially the interface between Quaternary and late Neogene deposits (Fig. 2b, top of Pliocene puddingstones; Kopf et al. 2008). While the Var river mouth and 1979 Nice Airport Landslide area (NAIL) are related to a Gilbert-type delta (Gilbert 1885, Savoye and Piper 1991, Dubar and Anthony 1995). This Gilbert-type delta was formed by the deposition of sediments from the western Alpine catchments of the Var river, which is characterized by high suspended sediment concentration, bedload 
transport, or deltaic sedimentary processes including wave reworking, geostrophic current, turbulent diffusion of seepage water in the basal aquifers and high density suspension flow of the fine-grained sediments (Anthony and Julian 1997). Reflectors are predominantly parallel to the seafloor with a southward dip, although some of the topset and foreset sequences are bent. Quite interestingly, the aquifer charges the underground in a spatially diverse manner, this way creating lenses of significant excess pore pressure in the vicinity of Nice Airport and other areas in the Var catchment region (see details in Emily et al., 2010). In contrast to the Quaternary section near Nice, the slope apron sediments of equivalent age show internal irregularities that may be caused by gravitational processes and hence directly relevant for this landslide study.

\subsection{Morphology and bathymetry}

The continental shelf of the French Ligurian margin is very narrow at $<3 \mathrm{~km}$ width, which tapers at the Baie des Anges and off the Nice airport to 0-900 m width. The shelf gradients of the outermost prodeltaic deposits are between $<1^{\circ}$ and $4^{\circ}$ (Cochonat et al. 1993, Mulder et al. 1994). The continental slope is very steep with an average slope angle of $11^{\circ}$ over the first $20 \mathrm{~km}$ from the coast and down to $\sim 2500 \mathrm{~m} \mathrm{depth}$. It is characterized by deeply-incised canyons generated by the Var and Paillon rivers with side-wall gradients up to $27^{\circ}$ (Fig. 1b, Pautot 1981, Klaucke et al. 2000, Ioualalen et al. 2010), and a large number of smaller steep-sided valleys, eroded surfaces, scars, ridges and gullies (Fig. 1b; see also Migeon et al. 2012 for detailed AUV bathymetry images). Based on high-resolution hull-mounted and AUV bathymetrical records, 250 landslide scars were detected at the shelf break and on the upper continental slope between 20 and $1000 \mathrm{~m}$ water depth and were categorized as very small, small, medium or large scars (Migeon et al. 2012). The very small to small scars are semi-circular to ellipsoidal shaped and mostly located at the shelf break as well as along the crest and on the flanks 
of the interfluves/ridges. The dimensions vary between 30 and $150 \mathrm{~m}$ width and 2 to $30 \mathrm{~m}$ height; however, most failure planes are less than $10 \mathrm{~m}$ deep (Klaucke and Cochonat 1999, Migeon et al. 2012). This is supported by overconsolidated core material near sedimentary hiatuses, which indicate removal of 4 and $9 \mathrm{~m}$ of sediment (Cochonat et al. 1993). The medium and large scars are usually located in the deeper regions of the continental slope, except the medium sized scar of the 1979 NAIL event (Figs. 1b, 3). The dimensions range from 150 to $500 \mathrm{~m}$ in width and 30 to $90 \mathrm{~m}$ in height (Migeon et al. 2012).

3. Data and Methods

\subsection{Geophysical data}

\subsubsection{Bathymetry}

During two geophysical surveys in 2000 and 2007, the Nice shelf and upper continental slope were mapped using a hull-mounted Simrad EM300 sonar system with a dominant frequency of $30 \mathrm{kHz}$ (see details in the Method section of Kopf et al. 2008). The swath bathymetric records were compiled to a Digital Terrain Model. The across-track resolution varies between 20 and $25 \mathrm{~m}$ according to the water depth (Fig. 1b, 3; Dan et al. 2007, Kopf et al. 2008, Sultan et al. 2010). These data, plus some of the AUV information (S. Migeon, pers. comm. 2012) was available for our models.

\subsection{2. $2 D$ chirp transects}

Given its small size and weight and operation from boats as small as a dinghy, chirp subbottom profilers represent an efficient and widely used geophysical technique to explore the shallow sub-seafloor sediments with a high resolution. In 2009, 100 2D 
transects were recorded in the study area south of Nice airport (Henry and Migeon 2009). The profiler uses primarily frequencies between 1.8 and $5.3 \mathrm{kHz}$, which are appropriate to achieve a decimeter-scale vertical resolution in shallow-water environments at. 4 hydrophones recorded the reflected waves. We have migrated the data using a p-wave velocity of $1500 \mathrm{~m} / \mathrm{s}$ in order to map prominent subbottom reflectors.

\subsection{Coring and sampling}

In 2001, four up to $17 \mathrm{~m}$ long Calypso cores were collected at the shelf break using the R/V Marion Dufresne (Dennielou et al. 2002, Sultan et al. 2004). This coring technique is highly effective in marine environments for recovering long sediment cores with minimum disturbance. The corer weighs 10 tons and consists of a $64 \mathrm{~m}$ long metal tube with a $14 \mathrm{~cm}$ diameter containing a high-pressure PVC liner with a $10 \mathrm{~cm}$ diameter. A mechanical trigger and a piston ensure uniform sampling of the sediment within the liner during the final free-fall, from about $1 \mathrm{~m}$ above the seabed (http://www.eurofleets.eu/np4/72.html).

More than 60 gravity cores with up to $5.3 \mathrm{~m}$ core recovery were collected at the shelf break and 1979 NAIL area using R/Vs Meteor and Poseidon (Kopf et al. 2008, 2009, 2012). The corer weighs $1.5-2.0$ tons and consists of a 2 or $6 \mathrm{~m}$ long metal tube containing an internal PVC liner with a $10 \mathrm{~cm}$ diameter (Emery and Dietz 1941). The cores were cut into sections of $1 \mathrm{~m}$ length, split, and first underwent lithological characterization.

The sediments in the study area are characterized as highly bioturbated, homogeneous, fine-grained hemipelagic deposits consisting of medium plasticity silty clay with 
scattered coarse beds of silt to sand (Cochonat et al. 1993, Klaucke et al. 2000, Dan et al. 2007, Sultan et al. 2008, Kopf et al. 2008, 2009, 2012).

\subsection{Sediment physical properties}

In situ and laboratory data sets were collected using conventional onshore and offshore static-CPTU measurements, Atterberg limits, one-dimensional compression tests, grain size analysis, and vane shear (vs) and fall cone penetration (fc) measurements on the split core face.

\subsubsection{In situ measurements}

In 1994, five deep onshore static-CPTU measurements were performed along the shoreline of the Nice airport by Sols Essais reaching up to $42 \mathrm{~m}$ penetration depth (Sols Essais, unpublished data, 1994, Dan 2007). Based on the CPT data the sediments along the Nice airport are characterized as normally- to slightly overconsolidated clay with embedded thin beds of coarse sediments, except for the upper $5 \mathrm{~m}$ of engineering fill. The corrected cone penetration resistance $\left(\mathrm{q}_{\mathrm{t}}\right)$ is between 0 and $3 \mathrm{MPa}$ in the hemipelagic deposits; however, prominent peaks in the coarse layers up to $5 \mathrm{MPa}$ were detected. Sultan et al. (2004) and Dan et al. (2007) mention a thick succession of sensitive clay at 30 to $42 \mathrm{~m}$ depth and a distinct clayey sand bed at $\sim 36.5 \mathrm{~m}$ depth.

In 2008, nine offshore static-CPTU tests were carried out using the IFREMER Penfeld device (Sultan et al. 2008, 2010). These tests focus on the geotechnical characterization of the prodelta deposits, in particular to identify and characterize existing shear zones potentially consisting of sensitive clays. The identified shear zones were described by significant drops of the $\mathrm{q}_{\mathrm{t}}$ and were detected between 8 and $28 \mathrm{~m}$ with an average depth 
of $22 \mathrm{~m}$. Sultan et al. (2010) remark that the shear zones are more pronounced in the measured sleeve friction $\left(\mathrm{f}_{\mathrm{s}}\right)$ measurements (see also Sultan et al. 2007) and can be characterized by a $\mathrm{f}_{\mathrm{s}}$ drop at 3 to $9 \mathrm{~m}$ depth.

From 2007 until 2012, 120 short dynamic-CPTU tests were collected on the Nice upper continental slope, at the Nice shelf and at the 1979 NAIL area (cruises M73/1: Kopf et al. 2008, P386: Kopf et al. 2009, STEP: N. Sultan, unpublished data, 2012, and P429: Kopf et al. 2012). Penetration depth varies depending on lithology, but usually does not exceed $5 \mathrm{~m}$ (Kopf et al. 2008, 2009, 2012). Results are detailed in the cruise reports and are also shown below where relevant to this study.

\subsubsection{Laboratory experiments}

Cores collected during French cruises (Sultan et al. 2004, Dan et al. 2007), were used for standard and advanced laboratory experiments with the aim of understanding the strength properties, consolidation state and sensitivity of the surficial sediments. The Multi Sensor Core Logging (MSCL) gamma density $(\rho)$ is $1.6-2.1 \mathrm{~g} / \mathrm{cm}^{3}$ for the upper continental slope (Cochonat et al. 1993, Sultan et al. 2004) and show higher values up to $2.2 \mathrm{~g} / \mathrm{cm}^{3}$ in the 1979 NAIL area (Dan et al. 2007). The compressional wave velocity ( $\mathrm{v}_{\mathrm{p}}$ ) is in the range of 1500 to $1700 \mathrm{~m} / \mathrm{s}$ (Sultan et al. 2004, Dan et al. 2007). The clay content falls in the range of 16 to $30 \%$ with an average grain size of 20 to $30 \mu \mathrm{m}$ (Cochonat et al. 1993, Klaucke et al. 2000, Sultan et al. 2004). The proportion of sandy silt to sand in the coarse interbeds is 20 to $90 \%$. The soil's sensitivity, described by the ratio of the intact and remolded undrained shear strength (e.g. Locat and Lefebvre 1985, Leroueil 2001), has been found to be $<5$ in the 1979 NAIL area (Dan et al. 2007).

We will use some of the existing data and blend them with new data to base our slope stability modeling on (see sections 4 and 5 below). 


\section{Methods}

\subsection{In situ piezocone penetrometer devices}

\subsubsection{IFREMER Penfeld static CPTU}

In this study, eight deep offshore static-CPTU tests collected with the IFREMER Penfeld penetrometer (Fig. 4) are used to recover in situ records from up to $28 \mathrm{~m}$ penetration depth (see also Sultan et al. 2010). This device pushes an oil-balanced $10 \mathrm{~cm}^{2}$ multisensor static-CPTU cone into the sediments and measures cone penetration resistance $\left(\mathrm{q}_{\mathrm{c}}\right), \mathrm{f}_{\mathrm{s}}$ and $\Delta \mathrm{u}$ using a KELLER differential pore pressure transducer. The geometry and accuracy class 1 of the piezocone follows ISO 22476-1 (2012). More details of this offshore static-CPTU instrument are described in Meunier et al. (2000, 2004).

\subsubsection{MARUM free-fall dynamic CPTU}

The MARUM shallow-water dynamic penetrometer relies on a $15 \mathrm{~cm}^{2}$ Geomil piezocone recording dynamic $\mathrm{q}_{\mathrm{c}}$, dynamic $\mathrm{f}_{\mathrm{s}}$, dynamic pore pressure behind the tip $\left(\mathrm{u}_{2}\right)$ using an absolute P transducer, and tilt/temperature (Fig. 5). In this study, 37 short dynamicCPTU measurements up to $5.4 \mathrm{~m}$ penetration depth were used and reprocessed (Kopf et al. 2008, 2009, 2012, and N. Sultan, unpublished data, 2012). The dynamic-CPTU cone is extended by $1 \mathrm{~m}$ long metal rods up to a maximum length of $8.5 \mathrm{~m}$ and hosts a pressuretight housing containing a microprocessor, standard secure digital memory card, tiltmeter, accelerometer, power supply and data interface module. The geometry and accuracy class 1 of the piezocone follows ISO 22476-1 (2012). Details regarding all mechanical and electronic components are presented in Stegmann et al. (2006) and Steiner et al. $(2012,2014)$. 


\subsection{Data processing of CPTU tests}

\subsubsection{Strain-rate correction}

Numerous studies have determined that both physical and hydraulic properties of clays, silts and sands depend non-linearly on the strain-rate (e.g. Eyring 1936, Casagrande and Shannon 1949, Suklje 1957). Dynamic-CPTU tests, with high penetration rates up to $10 \mathrm{~m} / \mathrm{s}$, show higher values compared to the static-CPTU parameters, and thus have to be corrected for this so-called strain-rate effect (e.g. Dayal et al. 1975, Stoll et al. 2007, Steiner et al. 2012). Previous studies illustrate that the modified inverse sin-hyperbolic equation, comprising the ratio of the dynamic and static penetration rate ( $v_{\text {dyn }}$ and $v_{\text {ref }}$ ) as well as SSC, is best suited for the strain-rate correction of clays (e.g. Randolph 2004, Steiner et al. 2014), described as follows for the three CPTU parameters:

$q_{t, q-s}=\frac{q_{t, d y n}}{1+\frac{\mu_{C P T U, q t}}{\ln (10)} \cdot \operatorname{arcsinh} \frac{v_{d y n} \cdot d_{d y n}}{v_{r e f} \cdot d_{r e f}}}$,

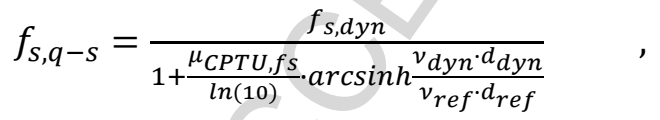

$\Delta u_{2, q-s}=\frac{\Delta u_{2, d y n}}{1+\frac{\mu_{C P T U, \Delta u}}{\ln (10)} \cdot \operatorname{arcsinh} \frac{v_{d y n} \cdot d_{d y n}}{v_{r e f} \cdot d_{r e f}}}$

where $\mathrm{q}_{\mathrm{t}, \mathrm{dyn}}$ \& $\mathrm{q}_{\mathrm{t}, \mathrm{q}-\mathrm{s}}$ are the dynamic and quasi-static corrected cone penetration resistances (Eq. 1), $\mathrm{f}_{\mathrm{s}, \mathrm{dyn}} \& \mathrm{f}_{\mathrm{s}, \mathrm{q}-\mathrm{s}}$ are the dynamic and quasi-static measured sleeve friction (Eq. 2), $\Delta \mathrm{u}_{2, \text { dyn }} \& \Delta \mathrm{u}_{2, \mathrm{q}-\mathrm{s}}$ are the dynamic and quasi-static excess pore pressures measured behind the tip (Eq. 3), and $\mathrm{d}_{\mathrm{dyn}} \& \mathrm{~d}_{\mathrm{ref}}$ are the diameters of the dynamic- and static-CPTU piezocones (see also Randolph 2004, Mitchell and Soga 2005, Steiner et al. 2014). Finally, if using strain-rate corrected (quasi-static) CPTU parameters, all existing geotechnical solutions can be directly used. 


\subsubsection{In situ intact undrained shear strength}

The determination of the in situ intact undrained shear strength $\left(\mathrm{s}_{\mathrm{u}, \mathrm{q}}\right)$ is based on both theoretical solutions (i.e. classical bearing capacity theory, Terzaghi 1943; cavity expansion theory, Skempton 1951; strain path theory, Baligh 1985) and empirical correlations (Aas et al. 1986). According to simplifications in the theoretical solutions with respect to the soil behavior, failure mechanism and boundary condition, the empirical correlation is preferred in geotechnical practice and scientific research, and is described as follows:

$s_{u, q t}=\frac{\left(q_{t}-\sigma_{V 0}\right)}{N_{k t}}$,

where $\sigma_{\mathrm{vo}}$ is the in situ total overburden stress, $\mathrm{N}_{\mathrm{kt}}$ is the empirical cone penetration resistance factor, and $\mathrm{q}_{\mathrm{t}, \mathrm{q}-\mathrm{s}} \& \mathrm{q}_{\mathrm{t}, \mathrm{ref}}$ are the corrected cone penetration resistance (Lunne et al. 1997, Low et al. 2010). The additional subscripts for $q_{t}$ reflect the type of instrument ("q-s" for the dynamic-CPTU instrument and "ref" for the static-CPTU device).

\subsubsection{In situ total unit weight}

The correct determination of the in situ total unit weight $\left(\gamma_{\mathrm{t}}=\rho_{\mathrm{t}}{ }^{*} \mathrm{~g}\right)$ is required for the assessment of the in situ total overburden stresses, and is imperative for many CPTU correlations (e.g. Lunne et al. 1997). The $\rho_{\mathrm{t}}$ is the in situ bulk density in $\mathrm{g} / \mathrm{cm}^{3}$, and $\mathrm{g}$ is the gravity $\left(9.81 \mathrm{~m} / \mathrm{s}^{2}\right)$. An empirical equation, developed by Mayne et al. (2010), is used to directly determine $\gamma_{t}$ from the penetration depth $(z), q_{t}$ and $f_{s}$, expressed as:

$\gamma_{t}=11.46+0.33 \cdot \log (z)+3.10 \cdot \log \left(f_{s}\right)+0.70 \cdot \log \left(q_{t}\right)$, 
where the in situ total unit weight is here given in $\mathrm{kN} / \mathrm{m}^{3}$ or $\mathrm{kPa} / \mathrm{m}$. Mayne et al. (2010) performed multiple regression analyses comprising 44 sites, where unit weight tests, shear wave velocity measurements and CPTU datasets were collected. The equation is valid for clayey to sandy deposits, except diatomaceous clays and highly calcareous sediments (Mayne et al. 2010).

\subsection{Laboratory experiments}

\subsubsection{Index properties and grain size distribution}

Atterberg limits, i.e. the liquid limit $\left(\omega_{\mathrm{L}}\right)$ and plastic limit $\left(\omega_{\mathrm{P}}\right)$, were determined using a Casagrande-percussion and an electronically driven apparatus. Both limits are used to determine the plasticity $\left(\mathrm{I}_{\mathrm{P}}\right)$ and liquidity index $\left(\mathrm{I}_{\mathrm{L}}\right)$, which together with $\omega_{\mathrm{L}}$ and moisture content $(\omega)$ provide the basis for soil classification and correlation of sediment properties (BS 1377-2 1990, BS 5930 1999).

Grain size distribution was analyzed using a Coulter Counter $L S$-13320 laser particle size analyzer. The Coulter Counter LS-13320 measures grain size in 117 classes ranging from 0.04 to $2000 \mu \mathrm{m}$ as a volume percent (Syvitski 2007). The associated soil classification is based on ISO 14688-1 (2002). Given that many of the lithologies comprise significant amounts of clay given their low strength and deformed state from visual inspection of the core, we have used detergents to disaggregate larger clayey particles, which may be bound by organic matter. It is well accepted that the Coulter Counter technique underestimates the clay size fraction owing to aggregation, however, our comprehensive work on shallow as well as deep core materials attests that (i) the disaggregation using detergents and an ultrasonic bath is effective, and (ii) clay content correlates the frictional strength in shear tests well (Kopf et al. 2011). 


\subsubsection{Shear strength measurements}

Standard vane shear experiments were performed to determine the $s_{u, v s}$. A four-bladed vane with a length / diameter of $12.5 \mathrm{~mm}$, height of $6.25 \mathrm{~mm}$ and a constant rotation rate of $90^{\circ} / \mathrm{min}$ are used (Blum 1997). A fall cone device was utilized with a defined weight of $80.51 \mathrm{~g}$ and $30^{\circ}$ cone geometry in order to determine the intact fall cone penetration shear strength $\left(\mathrm{s}_{\mathrm{u}, \mathrm{fc}}\right)$ (Hansbo 1957). All cores of this study were tested using both techniques at a sampling interval of $0.05-0.1$ (fc) to $0.5 \mathrm{~m}$ (vs), with several repeat measurements for fall cone impact if the core was homogeneous and recovery high.

\subsubsection{Oedometer and permeameter experiments}

The coefficient volume compressibility $\left(\mathrm{m}_{\mathrm{v}}\right)$ and Young's modulus (E) were evaluated using one-dimensional compression tests. These oedometers consist of a metal ring retaining the sediment specimen and preventing lateral expansion of the material. The diameter and height of the metal ring are $3.6 \mathrm{~cm}$ and $1.5 \mathrm{~cm}$. The samples were incrementally loaded up to $6.3 \mathrm{MPa}$ axial stress (i.e. effective overburden stress with zero excess pore pressure) and associated settlements due to drainage were recorded resulting in a non-linear relationship between the settlements and axial stresses. The $\mathrm{m}_{\mathrm{v}}$ and $\mathrm{E}$ are calculated using this non-linear relationship, defined as:

$\mathrm{m}_{\mathrm{v}}=\frac{\Delta \mathrm{H}_{\text {inc }}}{\mathrm{H}_{\mathrm{ini}}} \cdot \frac{1}{\Delta \sigma_{\text {'inc }}^{\prime}}$

$\mathrm{E}=\frac{1}{\mathrm{~m}_{\mathrm{v}}} \cdot \frac{(1+v) \cdot(1-2 \cdot v)}{(1-v)}$

where $\Delta \mathrm{H}_{\text {inc }}$ is the difference between the height of the specimen at the start of a loading increment $\left(\mathrm{H}_{\text {ini }}\right)$ and the height at the end of that increment, $\Delta \sigma^{\prime}$ inc is the effective stress difference related to several loading stages, and $v$ is the Poisson ratio assumed at about 
0.3 (see BS 1377-5 1990 for details). In addition, regression analyses using all load increments up to $800 \mathrm{kPa}$ (i.e. $\sim 115 \mathrm{~m}$ depth with respect to the numerical slope stability models) are carried out to evaluate the average $E$ for the seabed $\left(E_{\text {ref }}\right)$ and the complemented gradient with depth $\left(\mathrm{E}_{\text {inc }}\right)$.

The coefficient of permeability $\left(\mathrm{k}_{\mathrm{f}}\right.$, here given in $\mathrm{m} / \mathrm{s}$ ) was measured using a permeameter triaxial cell and core specimens with a diameter of $2.5 \mathrm{~cm}$ and height of $2.5-4 \mathrm{~cm}$. Specimens at different depth were loaded by their in situ effective overburden stress $\left(\sigma^{\prime}{ }^{\prime}\right)$ and $\mathrm{k}_{\mathrm{f}}$ are calculated. A temperature correction was performed using a correction factor of 0.771 in order to convert the measurements at $20^{\circ} \mathrm{C}$ to parameters at $10^{\circ} \mathrm{C}$ (see BS 1377-6 1990 for details), which more closely reselmbles Mediterranean Sea bottom water conditions of ca. $13^{\circ} \mathrm{C}$. In addition, the coefficient of consolidation $\left(c_{v}\right.$, here given in $\left.\mathrm{m}^{2} / \mathrm{s}\right)$ is based on the relationship between $\mathrm{k}_{\mathrm{f}}$ and $\mathrm{m}_{\mathrm{v}}$, expressed as:

$\mathrm{c}_{\mathrm{v}}=\frac{\mathrm{k}_{\mathrm{f}}}{\mathrm{m}_{\mathrm{v}} \cdot \gamma_{\mathrm{w}}} \quad$,

where the $\gamma_{\mathrm{w}}$ is the unit weight of water, here given in $\mathrm{kN} / \mathrm{m}^{3}$ or $\mathrm{kPa} / \mathrm{m}$ (Terzaghi et al. 1996). Based on $c_{v}$, the "non-dimensional velocity" is determined, which is a measure for the degree of consolidation during penetration (Finnie and Randolph 1994, Steiner et al. 2014). The non-dimensional dynamic velocity $\left(\mathrm{V}_{\mathrm{dyn}}\right)$ and non-dimensional static velocity $\left(\mathrm{V}_{\text {ref }}\right)$ are expressed as:

$$
\begin{aligned}
& V_{d y n}=\frac{v_{d y n} \cdot d_{d y n}}{c_{v}} \\
& V_{r e f}=\frac{v_{r e f} \cdot d_{r e f}}{c_{v}}
\end{aligned}
$$

\subsection{Slope stability analyses}


2D numerical models were developed using the Plaxis finite element software (Vermeer 1979) to take into consideration realistic natural boundary conditions. The Plaxis model is a plane strain numerical calculation. A plane strain calculation use an almost uniform cross section with the corresponding stresses and loading conditions. The vertical stresses in z-direction (perpendicular to the cross section) are fully considered, but the displacements and strains in this direction are zero. The plaxis program uses 15-node triangular elements. The geometrical constraints are derived from the 2D chirp transects acquired during the Haligure project (P. Henry, unpubl. data). The linear elastic perfectly plastic Mohr Coulomb constitutive law is used for undrained effective stress analyses. These analyses utilize $s_{u}$ at the seabed and assume a linear increase of undrained shear strength with depth as direct input parameters. This linear increase is constrained by the wealth of CPTU data, fall-cone and vane shear measurements of core specimens, and is further supported by the $s_{u}$ vs. depth trends in Leynaud \& Sultan (2012) (see section 5.3.2. in particular).

In the numerical calculations two steps were conducted. The first step includes the calculation of the initial effective stresses depending on the model geometry. This calculation illustrates the effective minor and major principal stresses at any point of the model. The second step deals with the calculation of the factor of safety and the associated failure geometry. In numerical calculations, the so called $\phi / c$-reduction is used, as described by the gradual reduction of the undrained shear strength until the FoS is unity. Hence, the effective stress conditions change and also the displacements increase leading to a development of a shear band. FoS is defined as the ratio of the actual strength compared to the minimum strength required for equilibrium utilizing an incremental reduction in shear strength. We will elaborate on the structural constraints of our models in the Results section below. 


\section{Results}

Our general approach in this study is to incrementally build a pseudo-3D model of the area south of Nice with the data available. In a first step, we use the seabed reflector of the chirp profiles and compare it with the associated bathymetrical transects for corroboration. This way we obtain a 3D image of the seafloor bathymetry and underlying reflectors from chirp surveying. In a second step, the sediment physical properties data from cores are measured (section 5.1) and combined with Chirp data (section 5.2.1.). Third, data from cone penetration testing and geotechnical laboratory experiments are used to calculate the in situ total weight (section 5.2.3.) needed for the models. This is followed by extrapolating the geotechnical information and integration of those data to ground truth the shallow chirp reflectors (section 5.2.4.). A fifth step then encompasses 2D finite element analyses to evaluate the undrained stability of the shelf and shelf break near the Nice international airport, and to assess different maximum shear failure geometries and associated volumes of potential landslides (section 5.2.5.).

\subsection{Sediment properties}

A sedimentological description of the shelf and shelf break off the Nice international airport was carried out using one long Calypso core and 10 short gravity cores (see Fig. 3 for location). The visual core log of gravity core 919-gc serves as an example describing the lithology of the upper $4 \mathrm{~m}$ of sediments (Fig. 6a). It shows predominantly silty clay/clayey silt with cm-thin to dm-thick intermediate layers of clay and irregularly distributed silty to sandy beds. The silt beds are up to $20 \mathrm{~cm}$ thick and the sand beds are less than $5 \mathrm{~cm}$ thick. 
The fall cone and vane shear experiments performed every 5-10 cm were used to verify and validate the calculated $\mathrm{s}_{\mathrm{u}, \mathrm{qt}}$ taken from two strain-rate corrected (quasi-static) CPTU tests (Eq. 4), in particular, to confirm the applied empirical $\mathrm{N}_{\mathrm{kt}}$ factor (Fig. 6b, see also section 4.1.2). Consequently, $\mathrm{s}_{\mathrm{u}, \mathrm{qt}}$ from CPTU profiles $954-3$ and 13-st are compared to $\mathrm{S}_{\mathrm{u}, \mathrm{fc}}$ and $\mathrm{s}_{\mathrm{u}, \mathrm{v}-\mathrm{s}}$ measured on core 919 -gc. An $\mathrm{N}_{\mathrm{kt}}$ factor of 20 is applied due to the existence of free gas from observations in cores and excursions in the CPT profiles (Sultan et al. 2008, 2010; Leynaud and Sultan 2010). Good agreement is found between both in situ records, fall cone and vane shear experiments, except two $20 \mathrm{~cm}$ thick coarse-grained beds between 1 and $2 \mathrm{~m}$ depth, where an unrealistically low $\mathrm{s}_{\mathrm{u}, \mathrm{fc}}$ is observed. From 3.3 to $4.0 \mathrm{~m}$ depth, $\mathrm{S}_{\mathrm{u}, \mathrm{fc}}$ shows several positive peaks up to $52 \mathrm{kPa}$ and a slightly higher trend compared to the $s_{u, q t}$, potentially related to shell fragments encountered in the homogeneous clay section or due to compaction of the sediments during core recovery. Good agreement can also be seen comparing $s_{u, q t}$ with $s_{u, v s}$ of Calypso core 2470-cpc (Sultan et al. 2004), although the lower sampling rate of $15 \mathrm{~cm}$ causes a sketchier match (Fig. 6b). From a geotechnical standpoint, $\mathrm{s}_{\mathrm{u}}$ varies between 2 and $5 \mathrm{kPa}$ at and close to the seabed, and an overall strength increase of $0.8 \mathrm{kPa} / \mathrm{m}$. Several peaks up to $12 \mathrm{kPa}$ are detected, usually related to coarse-grained layers (Table 1 and Figs. 6a, 6b).

The $\Delta \mathrm{u}_{2, \mathrm{q}-\mathrm{s}}$ profiles of CPT sites 954-3, 13-st and 14-st serve as examples to illustrate the difference between free gas-affected and -unaffected sediments (Fig. 6c and Fig. 3 for location). The first two profiles show sub-hydrostatic conditions, potentially related to free gas accumulation. The significant difference between the profiles is likely due to the different test locations with a distance of $\sim 125 \mathrm{~m}$ and potentially illustrates the high variability of the gas content. Conversely, the third profile (14-st) was collected in an area on the upper continental slope (see Fig. 3 for location) affected by erosion and shows a constant increase with $\sigma^{\prime}$, but may be unaffected by the presence of free gas. The $\Delta \mathrm{u}_{2, \mathrm{q}-\mathrm{s}}$ parameters are as low as $-25 \mathrm{kPa}$ for the free gas-affected tests, while the 
unaffected profiles show values less than $20 \mathrm{kPa}$ for the upper $4 \mathrm{~m}$ of sediments (Fig. 6c).

The grain size distribution was evaluated for gravity cores 926-gc and 952-gc using a sampling interval of $10 \mathrm{~cm}$, and was supplemented by additional samples extracted from cores 935-gc and 936-gc. The clayey to sandy sediments are characterized by up to $30 \%$ clay content, up to $87 \%$ silt proportion and less than $30 \%$ sand proportion (Table 1 ). The high sampling rate further allows us to neatly correlate the grain size data with the visual core logs of the stratified successions. Figure 7 illustrates the cumulative distribution (ISO 14688-1 2002) including three narrow bands of grain size distribution for the clay to silty clay, silt and sandy silt to sand. The clay content for the clayey silt to silty clay, defined as fine-grained sediments hereafter, varies between 20 and 30\%. The clay content for the silt and sandy silt to sand, defined as coarse-grained sediments hereafter, show values in the range of 15 to $21 \%$ and 10 to $18 \%$. An increased amount of the sand proportion is observed comparing fine-grained and coarse-grained sediments (Fig. 7). $\omega$ varies between 32 and $45 \%$ fraction of the wet mass. The $\omega_{\mathrm{L}}$ are up to $40 \%$ and $\omega_{P}$ are less than 20\%. Both limits result in an $I_{P}$ between 10 and $25 \%$. The combination of $I_{P}$ and $\omega_{\mathrm{L}}$ describes a low to medium plastic clay, low plastic silt and minor cohesive sand using the Casagrande "A-line" soil classification chart (BS 5930 1999).

Volume compressibility and Young's modulus were assessed using oedometer tests on surficial sediments taken from cores 925-gc and 939-gc recovered in the 1979 NAIL area. Four tests were performed on samples deposited prior to and after the 1979 NAIL event. Volume compressibility falls between $2^{*} 10^{-5}$ and $1 * 10^{-3} \mathrm{~m}^{2} / \mathrm{kN}$ for up to $35 \mathrm{~m}$ depth. In addition, Young's modulus is determined for sediments unaffected by mass movements, such as normally consolidated deposits, and for sediments influenced by slide events or erosional processes. Regression analyses result in Young's modulus (E) 
up to $7 \mathrm{MPa}$ for the seabed ( $\left.\mathrm{E}_{\mathrm{ref1} 1}\right)$, with $\mathrm{E}$ versus depth ( $\left.\mathrm{E}_{\text {inc1 }}\right)$ varying between 1.0 and 1.3 $\mathrm{MPa} / \mathrm{m}$ for the unaffected sediments. The affected sediments reflect 3.5 times higher values at the seabed $\left(\mathrm{E}_{\mathrm{ref} 2}\right)$ and the $\mathrm{E}_{\mathrm{inc} 2}$ is up to 1.4 times higher. The vertical and horizontal $\mathrm{k}_{\mathrm{f}}$ values were measured on three core specimens of gravity cores 958 -gc and 957-gc in order to evaluate the anisotropy of permeability. Vertical $\mathrm{k}_{\mathrm{f}}$ ranges between $1.2^{*} 10^{-9}$ and $1.9^{*} 10^{-9} \mathrm{~m} / \mathrm{s}$, while horizontal $\mathrm{k}_{\mathrm{f}}$ values are up to 1.3 times higher and hence favor horizontal (i.e. layer-parallel) flow. Volume compressibility supplemented by permeability were used to determine the coefficient of consolidation $\left(\mathrm{c}_{\mathrm{v}}\right)$, which is higher than $2.7^{*} 10^{-6} \mathrm{~m}^{2} / \mathrm{s}$ (see also Table 1 for details). The "non-dimensional velocities" (Eqs. 9, 10) exceed a value of 30; thus, all static- and dynamic-CPTU tests were performed under fully undrained conditions (Finnie and Randolph 1994, Steiner et al. 2014).

\subsection{Risk assessment}

In order to model the potential risk of failure of the Nice slope, we further have to process our data. We first define the geometrical, lithological, and then geotechnical constraints before a slope stability analysis can be executed.

\subsubsection{Geometrical and lithological constraints}

Two chirp seismic transects are chosen for the lithological/geometrical modeling of the sub-seafloor sediments and to identify coarse-grained and potential weak layers. The first transect (ha100) is located south of the center shelf (Fig. 8a) and the second one (ha102) is located at the western part of the shelf (Fig. $8 \mathrm{~b}$ and Fig. 3 for location).

For ground-truthing purposes, the modeling is supplemented by core logs (see as example Fig. 6a) and strength profiles (Table 2, Figs. 8c, 8d). This combination enabled us to identify three different coarse-grained layers. The first one is characterized by 
$15 \mathrm{~cm}$-thick silt and $5 \mathrm{~cm}$-thick sandy silt to sand beds at 1 to $2 \mathrm{~m}$ depth, as seen in many CPTU deployments and gravity cores. Here, the shear strength is 1.5- to 2-times higher compared to the surrounding sediments. At 2.5 to $3 \mathrm{~m}$ depth, the second layer shows an alternating sequence of clay, silt, sandy silt to sand with a thickness of $50 \mathrm{~cm}$ including a 1.5-fold increase in strength. The third layer, at a depth of $4-5.5 \mathrm{~m}$, is a $10 \mathrm{~cm}$ thick sandy silt to sand bed with significant peak strengths up to $30 \mathrm{kPa}$ (Figs. 8c, 8d). Figure $8 \mathrm{~d}$ depicts also a decreased $\mathrm{s}_{\mathrm{u}}$ behavior when going from the shelf to the shelf break.

Beyond $6.5 \mathrm{~m}$ depth, a weak zone with a maximum thickness of $8.5 \mathrm{~m}$ is detected in the static-CPTU tests and Calypso core 2470-cpc (see also Sultan et al. 2010), and is mapped in the chirp transects (Figs. 8a, 8b). The exact thickness can only be validated in the static-CPTU tests (Fig. 9), but not in the chirp transects due to gas blanking or limited penetration depth. The weak zone consists of soft clays with a minimum $s_{u}$ of $6.5 \mathrm{kPa}$ and embedded silt, sandy silt to sand with strengths up to $26 \mathrm{kPa}$ (Figs. 8d, 9). A direct correlation between the surface of the weak zone and the eroded area beneath the morphological scar is found. Morphological steps at the shelf area are connected to the coarse-grained beds and the surface of the weak zone (Figs. 8a, 8b).

\subsubsection{Geotechnical constraints}

Detailed regression analyses were performed to determine the in situ undrained shear strength $\left(\mathrm{s}_{\mathrm{u}, \mathrm{reg}}\right)$, described by the $\mathrm{s}_{\mathrm{u}, \mathrm{reg}}$ at the seabed/surface $\left(\mathrm{d}_{1-3}\right)$ and $\mathrm{s}_{\mathrm{u}, \mathrm{reg}}$ gradient $\left(\mathrm{k}_{1-}\right.$ 3) with z. The subscript defines three different layers relevant for the $2 \mathrm{D}$ numerical transects. As an example, Figure 10 presents the $s_{u, q t}$ profile of the dynamic-CPTU test 23-st describing all results of the regression analysis. Here, $\mathrm{d}_{1}$ is $3.9 \mathrm{kPa}$ and $\mathrm{k}_{1}$ is $1 \mathrm{kPa} / \mathrm{m}$. In the regression analysis, prominent soft, stiff and probably coarse-grained beds are excluded using a robust regression solution (Holland and Welsch 1977) and 
visual engineering judgment (Fig. 10). Still, two distinct drops in the strength vs. depth profile made us divide our model into three distinct layers, while earlier workers extrapolated over $30 \mathrm{~m}$ or even $60 \mathrm{~m}$ using a linear regression (Leynaud \& Sultan 2012) (see Results section 5.3.2. below).

Almost all in situ and coring data (see Fig. 3 for location) are used to construct an areawide contour map of $\mathrm{d}_{1}$ with an interval of $0.5 \mathrm{kPa}$ (Fig. 11). The undrained shear strength properties $\left(\mathrm{s}_{\mathrm{u}, \text { reg }}\right.$ seabed and $\mathrm{s}_{\mathrm{u}, \text { reg }}$ gradient $)$ were generated using the elevation grid creator of the Global Mapper software. The software develops a triangulated irregular network using a Delaunay triangulation procedure. The $\mathrm{x}$ - and y-coordinates define the geometrical position (i.e. location of a gravity core, dynamic or static CPTU) and the elevation parameters are the $\mathrm{s}_{\mathrm{u}, \mathrm{reg}}$ seabed or $\mathrm{s}_{\mathrm{u}, \mathrm{reg}}$ gradient values depending on the model. The triangulation process results in two grids and contour plots of the regression undrained shear strength distribution of the Nice plateau (see Fig. 11). Hence, the maps in Figure 11 incorporate the bathymetry to obtain a cross-reference between the geotechnical data and the morphological features. For instance, low $d_{1}$ in the range of $2.5 \mathrm{kPa}$ are linked to several morphological scars and the increase of the slope angle $(\alpha)$, which can be seen in the southern part of the map. Figure 11 also illustrates six dynamic-CPTU benchmarks, denoted as sites 086-3, 954-3, 23-st, 539, 541 and 954-13-3, which help establishing a relationship between the map and the associated $d_{1}$ presented in Table 2. The first two tests describe the lowest $d_{1}$ of $2.5 \mathrm{kPa}$ located at the southern region, and the latter tests show distinctive higher $d_{1}$ up to $41 \mathrm{kPa}$ compared to the surrounding tests. Consequently, the latter two tests are probably located within an anthropogenic fill area and thus, are excluded because of the low amount of measurements to attain a realistic $s_{u, r e g}$ contour map. When excluding data influenced by anthropogenic fill (954-13-3 and 539; Fig. 11), the highest $\mathrm{d}_{1}$ up to $11.7 \mathrm{kPa}$ are located in the center part of the shelf (dynamic-CPTU test 541 ) and $\mathrm{d}_{1}$ varies between 4 and $6 \mathrm{kPa}$ at the eastern shelf break (Fig. 11). 
The seabed map is supplemented by an area-wide contour map describing $\mathrm{k}_{1}$ (Fig. 11). The minimum spacing is $0.1 \mathrm{kPa} / \mathrm{m}$ and the map is also linked to the bathymetry. The dynamic-CPTU test 541 shows the maximum $\mathrm{k}_{1}$ of $2.5 \mathrm{kPa} / \mathrm{m}$. The minimum $\mathrm{k}_{1}$ is $0.8 \mathrm{kPa} / \mathrm{m}$ observed at the dynamic-CPTU site 954-3. The dynamic-CPTU tests at the presumed anthropogenic fill area (sites 539, 954-13-3) show prominent peaks up to $220 \mathrm{kPa} / \mathrm{m}$ (see also Table 2) and very low penetration depths less than $0.2 \mathrm{~m}$, and were excluded in the sub-seafloor modeling. Moreover, due to different penetration depths of the dynamic-CPTU tests, the $\mathrm{k}_{1}$ contour map is validated for the upper $2 \mathrm{~m}$ of sediments at the central part of the shelf, and between 6.5 and $8.5 \mathrm{~m}$ at the shelf edge and shelf break (Fig. 9).

A relationship between $\alpha, k_{1}$ and $d_{1}$ is detected for the surficial sediments and is represented by a decrease of both $\mathrm{s}_{\mathrm{u}, \mathrm{reg}}$ parameters with increasing $\alpha$ (i.e. going from the center part to the southern and eastern shelf break). The $\mathrm{s}_{\mathrm{u}, \mathrm{reg}} / \alpha$ relationship is also shown by comparing static-CPTU tests (11-s3, 11-s4, 11-s5, 11-s6, 12-s2, 12-s3) closely located to the shelf edge (see also Sultan et al. 2010, Leynaud and Sultan 2010) and vane shear experiments on Calypso core 2470-cpc recovered at the shelf break (see also Sultan et al. 2004). Figure 9 presents the $\mathrm{s}_{\mathrm{u}, \mathrm{qt}}$ of the static-CPTU test 12 -s 3 using an $\mathrm{N}_{\mathrm{kt}}$ of 20 , and all other static profiles are illustrated as an $\mathrm{s}_{\mathrm{u}, \mathrm{reg}}$ range, except 11-s1 and 11-s2, because both tests are located in the center part of the shelf (see Fig. 3 for locations). The first $6.5 \mathrm{~m}$ long $\mathrm{s}_{\mathrm{u}, \mathrm{v}-\mathrm{s}}$ profile from Calypso station 2470 -cpc is 1.4 to 2.3 times lower compared to the $\mathrm{s}_{\mathrm{u} \text {,reg }}$ of the static-CPTU profiles, potentially related to slow deformation processes of a distinct, surficial sediment mass. In this upper sediment succession, $d_{1}$ exhibits values up to $7 \mathrm{kPa}$ and $\mathrm{k}_{1}$ is less than $1.2 \mathrm{kPa} / \mathrm{m}$. At $6.5 \mathrm{~m}$ depth for the staticCPTU tests and at $8.5 \mathrm{~m}$ depth for the $\mathrm{v}$-s experiments, a significant drop in $\mathrm{s}_{\mathrm{u}, \mathrm{reg}}$ and $\mathrm{s}_{\mathrm{u}, \mathrm{v}-\mathrm{s}}$ is detected to between 1.0 and $5.5 \mathrm{kPa}$. The regression range for the shallow sediments up to $28 \mathrm{~m}$ depth is quantified by $\mathrm{d}_{2-3}$ up to $3.9 \mathrm{kPa}$ and $\mathrm{k}_{2-3}$ varies between 0.8 and $1 \mathrm{kPa} / \mathrm{m}$ (Fig. 9). Table 3 summarizes the $\mathrm{d}_{2-3}$ and $\mathrm{k}_{2-3}$ parameters for 6.5 to $28 \mathrm{~m}$ depth 
of the static-CPTU tests and vane shear experiments on core 2470-cpc. In summary, the variability in the $\mathrm{k}_{1}$ and $\mathrm{d}_{1}$ contour maps as well as the static-CPTU tests reveal two distinct sediment units. The in-situ geotechnical parameters decrease when going from the inner shelf to the outer shelf (beyond the shelf edge or shelf break). The soil strength variability is only defined for the first/upper soil unit L1, which means that the "distinct units" vary horizontally and are most likely different facies in the former delta system (see Fig. 8). We will revisit this point when discussing the stratigraphic (i.e. vertical) units of the numerical model (see section 5.2.4. below).

\subsubsection{In situ total unit weight}

The $\gamma_{\mathrm{t}}$ is assessed using three static-CPTU tests and two adjacent dynamic-CPTU records at the shelf edge (stations 11-s6, 12-s2, 12-s3, 23-st and 24-st in Fig. 3). Figure 12 illustrates, for reasons of clarity, only the CPTU tests 11-s6, 12-s3 and 23-st; however, 11-s6 represents the maximum $\gamma_{\mathrm{t}}$ compared to the other CPTU tests. Good agreement can be seen between the static- and dynamic-CPTU tests, except the first $2 \mathrm{~m}$, which is probably attributed to the weight of the static device, which is consolidating the uppermost loose sediments quite substantially. A non-linear increase down to $28 \mathrm{~m}$ is observed and quantified up to an average $\gamma_{\mathrm{t}}$ of $17 \mathrm{kN} / \mathrm{m}^{3}$, except the drop to an average $\gamma_{\mathrm{t}}$ of $15 \mathrm{kN} / \mathrm{m}^{3}$ detected in the weak zone between 6.5 and $15 \mathrm{~m}$. Dan et al. (2007) present consolidation tests on gravity core specimens, which are used to calculate the total and submerged unit weights and which are connected to the lithological profile of onshore CPTU measurements. The test results show very good agreement with $\gamma_{t}$ except the first $4 \mathrm{~m}$, where the total unit weight is $10 \%$ higher. Below $20.5 \mathrm{~m}$ depth, oedometer data are approximately 5\% higher than offshore CPTU records (Fig. 12).

Leynaud and Sultan (2010) present MSCL total unit weight $(\gamma)$ data with values between 18 and $20 \mathrm{kN} / \mathrm{m}^{3}$ collected at the shelf and 1979 NAIL area, and similar $\gamma$ are derived 
from cores 926-gc and 2470-cpc. The MSCL data exhibit at least 1.3 times higher values compared to the in situ and consolidation tests. However, a convergent behavior of Calypso core 2470-cpc datasets is observed at depths greater than $15 \mathrm{~m}$.

\subsubsection{Geometry and intact undrained shear strength distribution}

The structural boundaries of the 2D numerical models are derived from the 2D chirp transects (see also Fig. 12 for details), but only cover the portion directly relevant for landsliding. A vertical extent down to $200 \mathrm{~m}$ and a horizontal prolongation of $75 \mathrm{~m}$ beyond the SE' end of profile ha100 (Fig. 14a) were applied to avoid edge effects. The maximum slope angle of $15.5^{\circ}$ is observed at ha102 (Fig. 14b). Both models are subdivided in vertical segments with a width less than $25 \mathrm{~m}$, and a 3-layer system (L1, L2 and L3) is implemented to take into account the $\gamma_{t}$ and $s_{u}$ distribution found in the existing data. With this model it is possible to realistically reproduce the variability of the unit weight and the undrained shear strength distribution (see Fig. 13). The $\gamma_{\mathrm{t}}$ of the surficial sediments (L1) and the weak zone (L2) is $15 \mathrm{kN} / \mathrm{m}^{3}$, and the layer thickness is $\leq 8.5 \mathrm{~m}$. The shallow to deep sediment succession (L3) has $\gamma_{\mathrm{t}}=17 \mathrm{kN} / \mathrm{m}^{3}$ (see also Fig. 13).

The shear strength distribution is quantified by $\mathrm{k}_{1-3}$ and $\mathrm{d}_{1-3}$ considering a linear increase with depth (see also Figs. 8, 11 for details). $\mathrm{k}_{1}$ varies between 0.8 and $1.1 \mathrm{kPa} / \mathrm{m}$ and $\mathrm{d}_{1}$ shows values up to $3.8 \mathrm{kPa}$ (see also Figs. 9, 10). For L2, the values of core 2470-cpc and the static-CPTU records are used (Table 3) except for the vertical segments of the areas eroded by landslides. Consequently, $\mathrm{k}_{2-3}$ varies between 0.88 and $0.95 \mathrm{kPa} / \mathrm{m}$, and the shear strength at the seabed is less than $1.95 \mathrm{kPa}$ (i.e. mean value of the static-CPTU tests; see Table 3). Both parameters are applied to calculate $\mathrm{d}_{2}$, which is between 7.9 and $9.4 \mathrm{kPa}$ depending on the thickness of L1. A similar procedure is used to evaluate the $k_{3}$ and $d_{3}$; thus, $k_{3}$ is equivalent to the $k_{2}$, and $d_{3}$ varies between 15 and 
$17 \mathrm{kPa}$ depending on the thicknesses of $\mathrm{L} 1$ and $\mathrm{L} 2$ (i.e. $\mathrm{d}_{3}$ is the regression parameter at the surface of L3). The 2D numerical models require also $\mathrm{d}_{2-3}$ and $\mathrm{k}_{2-3}$ for the landslide eroded areas (Figs. 14a, 14b). These parameters are derived from dynamic-CPTU tests performed in failed and landslide-prone areas, such as 036-1, 036-2, 14-st and 958-gc (see also Fig. 3 for location). Table 4 summarizes these CPTU tests, and the average $d_{2}$ is $6 \mathrm{kPa}$ with a $\mathrm{k}_{2}$ of $1.2 \mathrm{kPa} / \mathrm{m}$. A similar procedure as presented above is applied to determine the parameters for L3. It is worth noting that the left segments of the 2D numerical model utilize elastic properties in order to avoid unrealistic stress conditions and geometrical boundary effects.

\subsubsection{Results of the stability analyses}

Two 2D finite element analyses were performed to: (i) evaluate the undrained stability of the shelf and shelf break near the Nice international airport, and (ii) estimate different maximum shear failure geometries and volumes of potential landslides. We consider that two 2D numerical models realistically accommodate the geometrical constraints and stress-dependent undrained shear strength distribution of the soil as established within the wealth of data off Nice. The entire ha $\mathbf{1 0 0}$ cross section is $\mathbf{5 7 5} \mathrm{m}$ long and $200 \mathrm{~m}$ deep. It consists of 5392 elements with 43601 nodal points. The global ha 102 cross section is $425 \mathrm{~m}$ long and $150 \mathrm{~m}$ deep. It is made of 4669 elements with 37799 nodal points. When running the models, the effective stress conditions change and also the displacements increase leading to a development of a shear band. The soil above this shear band represents the failed material (i.e. rotational landslide). The failure depths of $20 \mathrm{~m}$ and $55 \mathrm{~m}$, as seen in Figure 14, are automatically generated (i.e. an outcome of the modeling) and show the maximum shear failure geometry of the numerical simulation, and not a pre-defined depth level where failure is postulated. 
Note, however, that the first level of $20 \mathrm{~m}$ is close to the reconstructed height of the package that was mobilized in 1979 from differential bathymetric analysis.

Figure 15a illustrates a concave-shaped progressive failure with a FoS equal 1, which is located south of the shelf center area. The failure length is $\sim 275 \mathrm{~m}$, depth is $55 \mathrm{~m}$ and the sediment volume having the potential to fail is up to 10 million $\mathrm{m}^{3}$ assuming a failure width between 700 and $800 \mathrm{~m}$. The assumed failure width considers that the progressive failure affects the entire eastern plateau (see Fig. 3). The depth of 55 mbsf is reflecting, in very broad terms and when averaging over several of the seismic reflection data acquired during cruise M73 (Kopf et al., 2008), the approximate depth level of the top of the Pliocene puddingstones. Hence this second scenario is suited to assess the consequences of a landslide that is not originating within the Quaternary but that would mobilize more or less all Quaternary material.

Two similar analyses were carried out at the western part of the shelf and shelf break. Figure 15c depicts the initial shear failure geometry with a length of $75 \mathrm{~m}$ and a depth of $20 \mathrm{~m}$, but a main failure geometry with $\sim 230 \mathrm{~m}$ length and $43 \mathrm{~m}$ depth is observed when integrating large deformations of the 2D finite element mesh and a FoS $\leq 1$ (Fig. 15b). The volume of a potential landslide is up to 6 million $\mathrm{m}^{3}$ assuming a failure width of 700 to $800 \mathrm{~m}$ (i.e. collapse of the entire eastern plateau).

\section{Discussion}

\subsection{Dynamic-CPTU device and sediment properties}

Comprehensive dynamic-CPTU datasets ( $\sim 140$ tests near the Nice international airport) reveal the ability of the MARUM dynamic-CPTU instrument to characterize complex surficial depositional environments in a time- and cost-effective way (Fig. 3, Kopf et al. 2008, 2009, 2012). Similar successful applications of the dynamic-CPTU instrument 
were performed in northern Norway (Steiner et al. 2012, Steiner et al. 2014) and Switzerland (Stegmann et al. 2007, Strasser et al. 2007), where penetration depths up to $8.3 \mathrm{~m}$ were reached in soft to normally consolidated clays. The dynamic nature of such an instrument results in higher $\mathrm{q}_{\mathrm{t}}, \mathrm{f}_{\mathrm{s}}$ and $\Delta \mathrm{u}_{2}$ values compared to the static-CPTU parameters, and thus have to be corrected using a modified inverse sin-hyperbolic equation, best suited for the strain-rate correction in clays (Eqs. 1, 2, 3, Randolph and Hope 2004, Steiner et al. 2014). Dynamic-CPTU tests in sediments with a clay content up to $30 \%$ (Table 1 ) require SSCs for $\mathrm{q}_{\mathrm{t}}$ and $\Delta \mathrm{u}_{2}\left(\mu_{\mathrm{CPTU}, \mathrm{qt}}\right.$ and $\left.\mu_{\mathrm{CPTU}, \Delta \mathrm{u}}\right)$ between 0.1 and 0.15 , and SSC for $\mathrm{f}_{\mathrm{s}}\left(\mu_{\mathrm{CPTU}, \mathrm{fs}}\right)$ of less than 1.4. Using these SSCs, good agreement between the static $s_{u, q t}$ of $12-s 3$ and quasi-static $s_{u, q t}$ of 24-st (Fig. 12d) and between quasi-static $s_{u, q t}$, $\mathrm{s}_{\mathrm{u}, \mathrm{fc}}$ and $\mathrm{s}_{\mathrm{u}, \mathrm{v}-\mathrm{s}}$ profiles (Fig. $6 \mathrm{~b}$ ) were found, except for the uppermost part of the profiles where compaction by heavy static devices or apparent overconsolidation may play a role. Other studies in similar sediments confirm these findings (Randolph and Hope 2004, Kopf et al. 2012, Steiner et al. 2012, 2014).

In previous studies, $\mathrm{N}_{\mathrm{kt}}$ was quantified between 8 and 20 for clays depending on the $\mathrm{I}_{\mathrm{P}}$ and overconsolidation ratio (e.g. Aas et al. 1986, Powell and Quarterman 1988, Robertson 2009). Low et al. (2010) combined a worldwide high-quality database for the assessment of $\mathrm{s}_{\mathrm{u}, \mathrm{qt}}$ and remolded undrained shear strength, and recommend $\mathrm{N}_{\mathrm{kt}}$ in the range of 11.5 to 15.5 based on the average undrained shear strength $\left(\mathrm{s}_{\mathrm{u}, \mathrm{ave}}\right)$ measured in direct simple shear, triaxial compression and extension experiments (see also Lunne et al. 2011). At the Nice study area, assumed average $\mathrm{N}_{\mathrm{kt}}$ of 12 and 15 according to Lunne et al. (1997) were used to calculate $s_{u, q t}$ for numerical 2D and probabilistic 3D slope stability assessments (Dan et al. 2007); however, in the probabilistic assessment, $\mathrm{s}_{\mathrm{u}, \mathrm{qt}}$ uncertainties were considered by $\mathrm{N}_{\mathrm{kt}}$ of 10 to 20 correspond to three standard deviations (Leynaud and Sultan 2010). Sultan et al. (2010) use comparisons of staticCPTU tests with v-s experiments on cores to determine $\mathrm{N}_{\mathrm{kt}}$ resulting in values of 14 for intact saturated sediments and 20 for sediments affected by dissolved and free gas. A 
similar decrease of $s_{u}$ between 20 and $25 \%$ was detected in two independent laboratory studies using v-s tests on fine-grained intact samples and sediments containing large gas bubbles (Nageswaran 1983, Sham 1989). In this study, comparisons of $\mathrm{s}_{\mathrm{u}, \mathrm{fc}}, \mathrm{s}_{\mathrm{u}, \mathrm{v}-\mathrm{s}}$ taken from laboratory experiments on cores and $s_{u, q t}$ obtained from contiguous CPTU tests show very good agreement when using an $\mathrm{N}_{\mathrm{kt}}$ of 20 (Fig. 6b), and is therefore appropriate for intact gassy sediments.

The associated $\Delta \mathrm{u}_{2, \mathrm{q}-\mathrm{s}}$ shows a negative response in the top soils at the shelf and shelf break (i.e. sub-hydrostatic pore pressures), but not in the landslide-prone or eroded regions (Fig. 6c and Fig. 3 for location). Seifert et al. (2008) describe such a negative response in $\Delta \mathrm{u}_{2, \mathrm{q}-\mathrm{s}}$ by the occurrence of free gas in the sediments. Two possibilities were discussed: (i) free gas accumulation due to decay of organic material resulting in variations of shear strength, in particular, an increase of the gas content reducing the intact undrained shear strength by about 20\% (e.g. Wheeler 1986, Brandes 1999), and (ii) buoyancy of free gas in fissures generated during penetration and along the rods of the dynamic-CPTU instrument causing sub-hydrostatic $\Delta \mathrm{u}_{2, \mathrm{q}-\mathrm{s}}$ (e.g. Seifert and Kopf 2011). In addition, X-ray scans and visual observations on 957-gc and 926-gc illustrate sub-vertical conduits (piping) with a diameter less than $10 \mathrm{~mm}$, which connect two silt layers. These conduits may be related to overpressure release and fluidization (Kopf et al. 2009, Stegmann et al. 2011). In low-permeability, fine-grained sediments with $\mathrm{k}_{\mathrm{f}}$ lower than $1.9^{*} 10^{-9} \mathrm{~m} / \mathrm{s}$ (Table 1 ), disruption of the sediment structure may be caused when pore pressure, as a result of fluid flow or gas accumulation, exceeds the minimum effective stresses and tensile strength of the material, known as hydro-fracturing (Andersen et al. 1994). Consequently, the observations of $\Delta \mathrm{u}_{2, \mathrm{q}-\mathrm{s}}$ and comparisons of $\mathrm{s}_{\mathrm{u}}$ near the Nice international airport reveal that this area is potentially affected by free gas having significant impact on the sediment properties (Figs. 6b, 6c, 9, 10, Sultan et al. 2010). 
The in situ and laboratory $\mathrm{s}_{\mathrm{u}}$ profiles yield values ranging between 2.5 and $12 \mathrm{kPa}$ over the first $4 \mathrm{~m}$ of sediments (Table 1 and Fig. $6 \mathrm{~b}$ ). This $\mathrm{s}_{\mathrm{u}}$ range is confirmed by an upper limit of $10 \mathrm{kPa}$ for normally-consolidated sediments and by a lower limit of $3 \mathrm{kPa}$ representing also the boundary between under-consolidated and normally-consolidated sediments derived from v-s experiments at the Nice upper continental slope (Cochonat et al. 1993) and similar limits were detected at the shelf break (Sultan et al. 2004). Dan et al. (2007) present average $\mathrm{s}_{\mathrm{u}, \mathrm{v}-\mathrm{s}}$ varying between 59 and $68 \mathrm{kPa}$ for the first $\sim 4 \mathrm{~m}$ below the seafloor within the 1979 landslide scar, while only $13 \mathrm{kPa}$ are found in the first $10 \mathrm{~m}$ of sediment at the eastern plateau area (Leynaud and Sultan 2010) and in parts of the results of this study (Table 1 and Fig. 6b). Note also that ring shear experiments at MARUM were also used to validate the fall cone and vane shear data, most importantly from the gravity core lithologies of the NAIL 1979 scar (Stegmann et al. 2013).

\subsection{Sub-seafloor modeling}

Data from 45 offshore CPTU tests and 11 cores collected at the eastern plateau near the Nice international airport are used to: (i) develop a detailed sub-seafloor model, and (ii) perform 2D numerical stability analyses (Figs. 8, 9, 10, 11, 15), enhancing former slope stability assessments (Dan et al. 2007, Leynaud and Sultan 2010). The sub-seafloor model and stability assessments take into account $s_{u}$ variability at a shallow level, in particular, the increase of the $s_{u}$ with depth using linear regressions defined in cells of up to $25 \mathrm{~m}$ horizontal length (Fig. 14). So, this model images more accurately the natural $\mathrm{s}_{\mathrm{u}}$ distribution than models using slope parallel layers with thicknesses up to $13 \mathrm{~m}$ and average $\mathrm{s}_{\mathrm{u}}$ parameters (Dan et al. 2007, Leynaud and Sultan 2010).

A comparison of the total unit weight obtained from CPTU tests (Mayne et al. 2010), MSCL logging and consolidation tests (i.e. moisture and density (MAD)) is used to 
evaluate the (in situ) total unit weight variability with respect to different measurement techniques (Fig. 13). The most common technique is using MAD tests and MSCL logging on core samples in the laboratory. Both experiments are highly sensitive to the quality of the cores (e.g. deformed samples; Skinner and McCave 2003), evaporation/shrinking processes during core preparation and storage (Gerland and Villinger 1995), and presence of free gas in the sediments (e.g. Nageswaran 1983). These processes can lead to an overestimation of the $\gamma_{\mathrm{t}}$ up to $30 \%$, in particular, for the surficial sediments (Fig. 12). The total unit weight derived from the CPTU records (Eq. 5) is not a direct measurement, but is a proxy for the $\gamma_{t}$, which were developed based on a multiple regression analysis using 215 datasets collected worldwide (Mayne et al. 2010). This proxy underestimates the $\gamma_{\mathrm{t}}$ at the seafloor (up to $2.5 \mathrm{~m}$ depth); however, very good agreement with the consolidation tests is observed at a shallow level (Fig. 12). Consequently, we favor the use of CPTU records to assess $\gamma_{t}$ for slope stability assessments (Figs. 13, 14). Moreover, the herein presented sub-seafloor model considers also the influence of free gas disrupting the sediment structure that reduces $s_{u}$ by up to $30 \%$ (Fig. 6b, Nageswaran 1983, Sham 1989, Sultan et al. 2010). This $s_{u}$ decrease (up to 2.3 times) when going from shelf to shelf break (Fig. 11a, 11b) correlates well with the findings mentioned by Dan et al. (2007) that a $\geq 15 \% \mathrm{~s}_{\mathrm{u}, \mathrm{q} t}$ reduction is required to generate medium to large shear bands, and gravitational and progressive failure (Fig. 14; Leynaud and Sultan 2010).

The existence of a potentially up to $8.5 \mathrm{~m}$ thick shallow weak zone, labeled as a possible shear zone by Sultan et al. (2010), is confirmed by two chirp transects (Figs. 8a, 8b). At the shelf region, the surface of the weak zone and surficial coarse-grained layers are connected to morphological steps or rupture-surface propagation, probably indicating the development of progressive failure (Figs. 8a, 8b). Petley et al. (2005) propose a fourstep conceptual model for the development of progressive failure in cohesive soils. The first step describes the development of microcracks, and is followed by the interaction 
and coalescence of these microcracks allowing the formation of a shear surface. The formation of a shear surface reduces the $s_{u}$ of the sediments, and can be seen by the $s_{u}$ drop of up to $5.5 \mathrm{kPa}$ in the in situ and coring data (Fig. 9). Pore pressure rise in the sandy silt to sand beds favors also the formation of a shear surface, and may be confirmed by the sub-vertical conduits in the less permeable clays connecting two silt layers (Fig. 6a, Kopf et al. 2009, Stegmann et al. 2011). Such coarse-grained sediments are also found in core 2470-cpc at depth between 15 and 17 m (Sultan et al. 2004, Dan 2007). Consequently, deeper coarse-grained beds may act as fresh-water aquifers, and leaching processes may develop weak zones acting potentially as detachment planes for larger landslides (Dan et al. 2007, Sultan et al. 2010). The moderate hydraulic anisotropy measured on samples, with up to 1.3 times higher horizontal $\mathrm{k}_{\mathrm{f}}$ values, is insufficient to channel fluid horizontally. Channeling may only occur along laterally extensive permeable sandy layers, which remain hypothetical (see section 5.1). The third step describes stress concentrations at the shear surface resulting in slow deformation processes, which are displayed by the morphological steps and a connection of the weak zone surface to the landslide eroded area is ascertained (Figs. 8a, 8b; Sultan et al. 2010). A fully developed shear surface and FoS of equal or less than unity cause initial failure, resulting in a small rotational slide with a failure height up to $20 \mathrm{~m}$, but the potentially existing weak layer has not much influence on the geometry of the rupture surface (Fig. 14c). Similar landslides were identified on the Nice upper continental slope using hull-mounted and AUV bathymetrical mapping (Migeon et al. 2012).

\subsection{Slope stability assessments}

Slow deformation processes are evaluated by partially drained to drained slope stability analyses, where the generated $\Delta \mathrm{u}$ has time to dissipate. In contrast, earthquake loading 
and rapid pore pressure increase due to high precipitation events in conjunction with low permeability sediments require undrained slope stability analyses, where the $\Delta \mathrm{u}$ not has time to fully drain. Long-term pore pressure records at the 1979 NAIL area reveal a significant correlation between precipitation events and $\Delta u$, associated with the beginning of the snowmelt and heavily rainfall events over a period of 3 months (Stegmann et al. 2011). In addition, a seismological network was installed covering the region between Nice and the Italian border (Courboulex et al. 2007). More than 500 micro-earthquakes recorded between 2000 and 2001 reveal a NNE alignment on the socalled Blausasc fault, which is probably the "hidden root of the Peille-Laghet fault". Simulations to assess the peak ground accelerations (PGAs) in the city of Nice were performed assuming a magnitude 5.7 earthquake if the entire $8 \mathrm{~km}$ portion of the Blausasc fault fails (Courboulex et al. 2007). The average PGAs were quantified between 0.3 to $1.5 \mathrm{~m} / \mathrm{s}^{2}$ and potentially strong enough to trigger small to large landslides (Fig. 14). Cyclic loading tests assuming a PGA of $1.5 \mathrm{~m} / \mathrm{s}^{2}$ show FoS close to 1 for a sediment succession with a thickness less than $10 \mathrm{~m}$ (Sultan et al. 2004).

In this study, the 2D numerical calculations show FoS equal to or less than 1 considering undrained behavior, free gas accumulation, large deformations of the 2D finite element mesh, and a surficial weak zone resulting in a shear failure depth between 20 and $43 \mathrm{~m}$ (Figs. 14b, 14c). The 1979 NAIL event took place in a depth range of 25 to $40 \mathrm{~m}$ (Mulder et al. 1997), and slope stability assessments considering a weak layer (i.e. soft, sensitive clays and embedded sandy silt to sand beds) and creeping result in a FoS equal to unity (Dan et al. 2007). However, a larger landslide with a shear band depth of up to $60 \mathrm{~m}$ can also occur at the eastern plateau near the Nice airport (Fig. 15a, Leynaud and Sultan 2010) mobilizing up to 10 million $\mathrm{m}^{3}$ of sediments and potentially acting as an initial landslide for a very large event. Deep seismic reflection transects reveal a strong, predominantly smooth reflector in a depth of 60 to $100 \mathrm{~m}$ (Fig. 2b, Kopf et al. 2008, 2009), and is potentially the interface between Quaternary gravels and late Neogene 
conglomerates (Fig. 2, Dubar and Anthony 1995). So, this transition zone probably acts as fresh-water aquifer in which excess pressures can be generated, resulting in a higher potential for liquefaction in combination with the decrease of the effective overburden stresses due to the initial landslide (Fig. 14a, Leynaud and Sultan 2010, Anthony and Julian 1997). A detailed characterization of the transition zone requires longer core drillings supplemented by sedimentological and geotechnical analyses on drilled specimens taken above and below this zone. This procedure is indispensable for obtaining a better understanding of the potential likelihood that a very large submarine landslide will occur. Moreover, such a large landslide has the potential to trigger a huge tsunami affecting the coastline of the French Rivera and have a catastrophic impact on social and economic life of this region.

\section{Conclusion}

An interdisciplinary approach in slope instability assessment is currently applied in coastal and nearshore environments (e.g. Nidelva fjord delta, L'Heureux et al. 2010; Finneidfjord, Vanneste et al. 2013). Such a modelling approach using sedimentological and geotechnical data is crucial to: (i) perform realistic numerical slope stability assessments, and (ii) obtain a better knowledge of the initiation and development of submarine landslides.

Numerical slope stability assessments need a thorough assessment of geotechnical properties that, for instance, where determined combining coring with static- and dynamic-CPTU techniques. The dynamic system is operated faster due to its dynamic nature and the static system can reach deeper targets. Consequently, the combination of both systems is a powerful, time- and cost-effective way to explore the surficial and shallow sub-surface sediments. 
Free gas growth in the sediment disrupts the sediment structure, and reduces the strength properties by up to $30 \%$ compared to the intact properties. At the shelf and shelf break area near the Nice international airport, a gas weakening of the intact undrained shear strength $\left(\mathrm{s}_{\mathrm{u}}\right)$ was detected using comparisons of static and dynamic CPTU tests with laboratory experiments on cored samples. These lower $s_{u}$ values reduce the factor of safety in slope stability assessments at the Nice eastern plateau, and potentially result in a higher likelihood that a tsunamigenic submarine landslide event with a failure depth of up to $100 \mathrm{~m}$ will occur. The corresponding target horizon for such a failure will likely be the top of the Upper Pliocene puddingstones, a sequence of massive conglomerates that are currently subject to disaggregation into the alluvial deposits of the Var river system, and a prominent permeable lithology in the Var aquifer system whose groundwater inputs account for about $20 \%$ of alluvial water recharge (Potot 2011). Such a landslide could mobilize approximately 25 Million $\mathrm{m}^{3}$ of sediment if restricted to the 1979 landslide vicinity alone (V. Spiess, pers. comm., 2010), could easily involve up to 10-times more material in case the plateau areas E and W of the 1979 scar fail, and would obviously have catastrophic socio-economic consequences for the French Riviera.

\section{Acknowledgements}

This manuscript benefitted tremendously from the detailed expert reviews by Michi Strasser and an anonymous referee as well as the superb handling and suggestions by editor David Piper. Grateful acknowledgements are made to Nabil Sultan (Ifremer) for access to the static-CPTU tests (Penfeld deployments), and to the scientific parties, chief scientists and associated organizations contributing with cruise materials relevant to this study. We also thank Christian Zoellner and Matthias Lange for technical assistance with the MARUM CPTU devices, Timo Fleischmann, Simon Haas, Sebastian Schlenzek 
and Gauvain Wiemer for their help during data acquisition, and Matt Ikari and Andre Hüpers for commenting on an early draft of this paper. The work presented in this paper was funded by MARUM - Center for Marine Environmental Sciences, University of Bremen and in-kind contributions from the parties involved (Ifremer, CEREGE). 


\section{References}

Aas, G., Lacasse, S., Lunne, T., Hoeg, K., 1986. Use of in situ tests for foundation design on clay. Publikasjon-Norges Geotekniske Institutt, 1-15.

Ai, F., Förster, A., Stegmann, S., Kopf A., 2014. Geotechnical characteristics and slope stability analysis of the deeper slope of the Ligurian margin, Southern France. Proceedings of the Beijing Landslide Forum, 6pp.

Andersen, K.H., Rawlings, C.G., Lunne, T., By, T.H., 1994. Estimation of hydraulic fracture pressure in clay. Canadian geotechnical journal 31, 817-828.

Anthony, E.J., Julian, M., 1997. The 1979 Var Delta landslide on the French Riviera: A retrospective analysis. Journal of coastal research 13, 27-35.

Anthony, E.J., Julian, M., 1999. Source-to-sink sediment transfers, environmental engineering and hazard mitigation in the steep Var River catchment, French Riviera, southeastern France. Geomorphology 31, 337-354.

Assier-Rzadkiewicz, S., Heinrich, P., Sabatier, P., Savoye, B., Bourillet, J., 2000. Numerical modelling of a landslide-generated tsunami: the 1979 Nice event. Pure and Applied Geophysics 157, 1707-1727.

Auffret, G.-A., Auzende, J.-M., Gennesseaux, M., Monti, S., Pastouret, L., Pautot, G., Vanney, J., 1982. Recent mass wasting processes on the Provencal margin (western Mediterranean), Marine slides and other mass movements. Springer, New York, pp. $53-58$

Auzende, J.-M., 1971. La marge continentale Tunisienne: Résultats d'une étude par sismique réflexion: Sa place dans le cadre tectonique de la Méditerranée Occidentale. Marine Geophysical Researches 1, 162-177. 
Baligh, M.M., 1985. Strain path method. ASCE Journal of Geotechnical Engineering 111, 1108-1136.

Baligh, M.M., Azzouz, A.S., Wissa, A.Z., Martin, R.T., Morrison, M.J., 1981. The piezocone penetrometer, Proceedings of the ASCE Conference on Cone Penetration Testing and Experience, Geotechnical Engineering Division, St. Louis, pp. 247-263.

Blum, P., 1997. Physical properties handbook: a guide to the shipboard measurement of physical properties of deep-sea cores, ODP Technical Note 26.

Brandes, H., 1999. Predicted and measured geotechnical properties of gas-charged sediments. International Journal of Offshore and Polar Engineering 9, 219-225.

BS 1377-2, 1990. Methods of test for soils for civil engineering purposes, Classification tests. British Standard Institution.

BS 1377-5, 1990. Methods of test for soils for civil engineering purposes, Compressibility, permeability and durability tests. British Standard Institution.

BS 1377-6, 1990. Methods of test for soils for civil engineering purposes, Consolidation and permeability tests in hydraulic cells and with pore pressure measurement. British Standard Institution.

BS 5930, 1999. Code of practice for site investigations. British Standard Institution.

Bryn, P., Berg, K., Forsberg, C.F., Solheim, A., Kvalstad, T.J., 2005. Explaining the Storegga slide. Marine and Petroleum Geology 22, 11-19.

Casagrande, A., Shannon, W.L., 1949. Strength of soils under dynamic load. Transmission ASCE 114, 755-772.

Cherchi, A., Montadert, L., 1982. Oligo-Miocene rift of Sardinia and the early history of the western Mediterranean basin. Nature 298, 736-739. 
Cochonat, P., Bourillet, J.F., Savoye, B., Dodd, L., 1993. Geotechnical characteristics and instability of submarine slope sediments, the nice slope (N-W Mediterranean Sea). Marine Georesources \& Geotechnology 11, 131-151.

Courboulex, F., Larroque, C., Deschamps, A., Kohrs-Sansorny, C., Gélis, C., Got, J., Charreau, J., Stéphan, J., Béthoux, N., Virieux, J., Brunel, D., Maron, C., Duval, A.M., Perez, J.-L., Mondielli, P., 2007. Seismic hazard on the French Riviera: observations, interpretations and simulations. Geophysical Journal International 170, 387-400.

Dan, G., 2007. Processus Gravitaires et Evaluation de la Stabilité des Pentes: Approches Géologique et Géotechnique. Application à la marge algérienne et à l'effondrement de l'aéroport de Nice en 1979. Université de Bretagne Occidentale, p. 365.

Dan, G., Sultan, N., Savoye, B., 2007. The 1979 Nice harbour catastrophe revisited: Trigger mechanism inferred from geotechnical measurements and numerical modelling. Marine Geology 245, 40-64.

Dannielou, B., and shipboard party, 2002. Rapport de campagne a la mer MD 124 / GEOSCIENCES 2 a bord du Marion Dufresne de Marseille (France) le 29/09/2001 a Patras (Greece) le 05/10/2001. Ref: OCE/2002/02.

Dayal, U., Allen, J., Jones, J., 1975. Use of an impact penetrometer for the evaluation of the in-situ strength of marine sediments. Marine Georesources \& Geotechnology 1, 7389.

Dubar, M., Anthony, E.J., 1995. Holocene environmental change and river-mouth sedimentation in the Baie des Anges, French Riviera. Quaternary Research 43, 329343.

Emery, K.O., Dietz, R.S., 1941. Gravity coring instrument and mechanics of sediment coring. Geological Society of America Bulletin 52, 1685-1714. 
Eyring, H., 1936. Viscosity, plasticity, and diffusion as examples of absolute reaction rates. The Journal of Chemical Physics 4, 283-291.

Fahlquist, D.A., Hersey, J.B., 1969. Seismic refraction measurements in the western Mediterranean Sea. Bulletin of the Institute of Oceanography Monaco 67, p. 52.

Finnie, I., Randolph, M., 1994. Punch-through and liquefaction induced failure of shallow foundations on calcareous sediments, Proceedings of the International Conference on Behaviour of Offshore Structures. Pergamon Press Oxford, UK, pp. 217-230.

Gennesseaux, M., Mauffret, A., Pautot, G., 1980. Les glissements sous-marins de la pente continentale niçoise et la rupture de câbles en mer Ligure (Méditerranée occidentale). Comptes Rendus de l'Académie des Sciences de Paris 290, 959-962.

Gerland, S., Villinger, H., 1995. Nondestructive density determination on marine sediment cores from gamma-ray attenuation measurements. Geo-Marine Letters 15, $111-118$.

Gilbert, G.K., 1885. The topographic features of lake shores, Annual Report. U.S. Geological Survey, pp. 75-123.

Guglielmi, Y., 1993. Hydrogéologie des aquifères plio-quaternaires de la basse vallée du Var (Alpes-Maritimes, France). Universite d'Avignon et des Pays de Vaucluse, p. 188.

Hansbo, S., 1957. A new approach to the determination of the shear strength of clay by the fall-cone test. Royal Swedish Geotechnical Institute, Stockholm.

Henry, P., Migeon, S., 2009. HALIGURE cruise: Fiche technique de fin de champagne.

Holland, P.W., Welsch, R.E., 1977. Robust regression using iteratively reweighted leastsquares. Communications in Statistics-Theory and Methods 6, 813-827.

Hsü, K., 1971. Origin of the Alps and western Mediterranean. Nature 233, 44-48. 
Ioualalen, M., Migeon, S., Sardoux, O., 2010. Landslide tsunami vulnerability in the Ligurian Sea: case study of the 1979 October 16 Nice international airport submarine landslide and of identified geological mass failures. Geophysical Journal International 181, 724-740.

ISO 14688-1, 2002. Geotechnical investigation and testing - Identification and classification of soil - part 1: Identification and description. International Organization for Standardization.

ISO 22476-1, 2012. Geotechnical investigation and testing - field testing - part 1: Electrical cone and piezocone penetration test. International Organization for Standardization.

Klaucke, I., Cochonat, P., 1999. Analysis of past seafloor failures on the continental slope off Nice (SE France). Geo-Marine Letters 19, 245-253.

Klaucke, I., Savoye, B., Cochonat, P., 2000. Patterns and processes of sediment dispersal on the continental slope off Nice, SE France. Marine Geology 162, 405-422.

Kopf, A.J., and shipboard party, 2008. Report and preliminary results of Meteor cruise M73/1: LIMA-LAMO, Berichte aus dem Fachbereich Geowissenschaften der Universität Bremen, No. 264, p. 169.

Kopf, A.J., and shipboard party, 2009. Report and preliminary results of Poseidon cruise

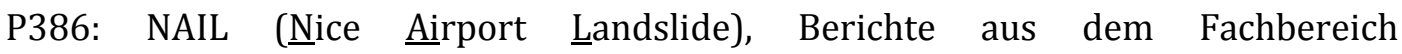
Geowissenschaften der Universität Bremen, No. 271, p. 161.

Kopf, A., Strasser, M., Monsees, N., Underwood, M., Guo, J., 2011. Particle size analysis of sediments recovered during IODP Expeditions 315 and 316, Sites C0001-C0008, Nankai Trough forearc, off Japan. Proc. IODP, 314/315/316, doi:10.2204/iodp.proc.314315316.207.2011 (19pp.) 
Kopf, A.J., and shipboard party, 2012. Report and preliminary results of Poseidon cruise P429: MEDFLUIDS, Berichte aus dem Fachbereich Geowissenschaften der Universität Bremen, No. 286, p. 80.

L'Heureux, J.-S., Hansen, L., Longva, O., Emdal, A., Grande, L., 2010. A multidisciplinary study of submarine landslides at the Nidelva fjord delta, Central Norwayimplications for geohazards assessments. Norwegian Journal of Geology 90, 1-20.

Le Borgne, E., Le Mouël, J.-L., Le Pichon, X., 1971. Aeromagnetic survey of south-western Europe. Earth and Planetary Science Letters 12, 287-299.

Le Pichon, X., Pautot, G., Auzende, J.-M., Olivet, J.-L., 1971. La Mediterranée Occidentale depuis l'Oligocene schema d'evolution. Earth and Planetary Science Letters 13, 145152.

Leroueil, S., 2001. Natural slopes and cuts: movement and failure mechanisms. Geotechnique 51, 197-243.

Leynaud, D., Sultan, N., 2010. 3-D slope stability analysis: A probability approach applied to the nice slope (SE France). Marine Geology 269, 89-106.

Locat, J., Lefebvre, G., 1985. The compressibility and sensitivity of an artificially sedimented clay soil: The Grande-Baleine Marine Clay, Québec, Canada. Marine Georesources \& Geotechnology 6, 1-28.

Low, H.E., Lunne, T., Andersen, K., Sjursen, M., Li, X., Randolph, M., 2010. Estimation of intact and remoulded undrained shear strengths from penetration tests in soft clays. Geotechnique 60, 843-859. 
Lunne, T., Andersen, K.H., Low, H.E., Randolph, M., Sjursen, M., 2011. Guidelines for offshore in situ testing and interpretation in deepwater soft clays. Canadian geotechnical journal 48, 543-556.

Lunne, T., Robertson, P., Powell, J., 1997. Cone penetration testing in geotechnical practice. Taylor \& Francis Group, London and New York.

Mayne, P., Peuchen, J., Bouwmeester, D., 2010. Soil unit weight estimation from CPTs, Proceedings of the CPT'10 2nd International Symposium on Cone Penetration Testing, Huntington Beach, California.

McKenzie, D., 1970. Plate tectonics of the Mediterranean region. Nature 226, 239-243.

Meunier, J., Sangouard, D., Lhuillier, B., 2000. A new seabed penetrometer, Proceedings of the Offshore Technology Conference, Houston.

Meunier, J., Sultan, N., Jegou, P., Harmegnies, F., 2004. First tests of Penfeld: a new seabed penetrometer, Proceedings of the 14th International Offshore and Polar Engineering Conference, Toulon, France, pp. 23-28.

Migeon, S., Cattaneo, A., Hassoun, V., Dano, A., Casedevant, A., Ruellan, E., 2012. Failure processes and gravity-flow transformation revealed by high-resolution AUV swath bathymetry on the Nice continental slope (Ligurian Sea), Submarine Mass Movements and Their Consequences. Springer, pp. 451-461.

Mitchell, J.K. Soga, K., 2005. Fundamentals of Soil Behavior. John Wiley \& Sons, New York.

Mulder, T., Savoye, B., Syvitski, J.P., 1997. Numerical modelling of a mid-sized gravity flow: the 1979 Nice turbidity current (dynamics, processes, sediment budget and seafloor impact). Sedimentology 44, 305-326. 
Mulder, T., Tisot, J.-P., Cochonat, P., Bourillet, J.-F., 1994. Regional assessment of mass failure events in the Baie des Anges, Mediterranean Sea. Marine Geology 122, 29-45.

Nageswaran, S., 1983. Effect of gas bubbles on the sea bed behaviour. University of Oxford, p. 250.

Pautot, G., 1981. Cadre morphologique de la Baie des Anges. Modèle d'instabilité de pente continentale. Oceanologica Acta 4, 203-212.

Petley, D.N., Higuchi, T., Petley, D.J., Bulmer, M.H., Carey, J., 2005. Development of progressive landslide failure in cohesive materials. Geology 33, 201-204.

Potot, C., 2011. Etude hydrochimique du système aquifère de la basse vallée du Var: apport des éléments traces et des isotopes ( $\mathrm{Sr}, \mathrm{Pb}, \mathrm{d} 180,226,228 \mathrm{Ra}$ ), Thèse de doctorat. Université Nice Sophia Antipolis, pp. 240.

Powell, J., Quarterman, R., 1988. The interpretation of cone penetration tests in clays, with particular reference to rate effects, Proceedings of the International Symposium on Penetration Testing. Balkema Publication, Orlando, pp. 903-909.

Randolph, M., 2004. Characterisation of soft sediments for offshore applications, Proceedings of the 2nd International Conference on Site Characterisation, Porto, pp. 209-231.

Randolph, M., Hope, S., 2004. Effect of cone velocity on cone resistance and excess pore pressures, Proceedings of the International Symposium on Engineering Practice and Performance of Soft Deposits. Yodagawa Kogisha Co., Ltd., pp. 147-152.

Rehault, J.-P., Boillot, G., Mauffret, A., 1984. The western Mediterranean basin geological evolution. Marine Geology 55, 447-477. 
Robertson, P., 2009. Interpretation of cone penetration tests - a unified approach. Canadian geotechnical journal 46, 1337-1355.

Savoye, B., Piper, D.J., 1991. The Messinian event on the margin of the Mediterranean Sea in the Nice area, southern France. Marine Geology 97, 279-304.

Seed, H., Seed, R., Schlosser, F., Blondeau, F., Juran, I., 1988. The landslide at the Port of Nice on October 16, 1979. Rep. No. UCB/EERC-88/10, Earthquake Engineering Research Center, University of California, Berkeley, CA.

Seifert, A., Kopf, A., 2011. Modified Dynamic CPTU Penetrometer for Fluid Mud Detection. Journal of Geotechnical and Geoenvironmental Engineering 138, 203-206.

Seifert, A., Stegmann, S., Mörz, T., Lange, M., Wever, T., Kopf, A., 2008. In situ porepressure evolution during dynamic CPT measurements in soft sediments of the western Baltic Sea. Geo-Marine Letters 28, 213-227.

Sham, W.K., 1989. The undrained shear strength of soils containing large gas bubbles. Queen's University of Belfast (1989).

Skempton, A., 1951. The bearing capacity of clays, Proceedings of the Building Research Congress, London, England, pp. 180-189.

Skinner, L., McCave, I., 2003. Analysis and modelling of gravity-and piston coring based on soil mechanics. Marine Geology 199, 181-204.

Sols Essais, 1994. Rapport Interne. Sols Essais (unpublished data).

Stegmann, S., Kopf, A., 2013. How stable is the Nice slope? - An analysis based on strength and cohesion from ring shear experiments. In Krastel, S., et al. (eds.), Proceedings $6^{\text {th }}$ meeting of Submarine Mass Movements and their consequences, Springer: 189-200. 
Stegmann, S., Sultan, N., Kopf, A.J., Apprioual, R., Pelleau, P., 2011. Hydrogeology and its effect on slope stability along the coastal aquifer of Nice, France. Marine Geology 280, $168-181$.

Stegmann, S., Villinger, H., Kopf, A.J., 2006. Design of a modular, marine free-fall cone penetrometer. Sea Technology 47, 27-33.

Steiner, A., Kopf, A.J., L'Heureux, J.-S., Kreiter, S., Stegmann, S., Haflidason, H., Moerz, T., 2014. In-situ dynamic piezocone penetrometer tests in natural clayey sediments - a reappraisal of strain-rate corrections. Canadian Geotechnical Journal, 51(3): 272-288, 10.1139/cgj-2013-0048.

Steiner, A., L'Heureux, J.-S., Kopf, A.J., Vanneste, M., Longva, O., Lange, M., Haflidason, H., 2012. An In-Situ Free-Fall Piezocone Penetrometer for Characterizing Soft and Sensitive Clays at Finneidfjord (Northern Norway), Submarine mass movements and their consequences. Springer, pp. 99-109.

Stoll, D., Sun, Y.-F., Bitte, I., 2007. Seafloor properties from penetrometer tests. IEEE Journal of Oceanic Engineering 32, 57-63.

Suklje, L., 1957. The analysis of the consolidation process by the isotaches method, Proceedings of the 4th International Conference on Soil Mechanics and Foundation Engineering, London, pp. 200-206.

Sultan, N., 2012. STEP cruise (R/V Europe) (unpublished data).

Sultan, N., and shipboard party, 2008. Prisme Cruise (R/V Atalante Toulon-Toulon; 2007): Reports and Preliminary Results, IFREMER Internal Report, Ref: IFR CB/GM/LES/08-11.

Sultan, N., Cochonat, P., Canals, M., Cattaneo, A., Dennielou, B., Haflidason, H., Laberg, J., Long, D., Mienert, J., Trincardi, F., 2004. Triggering mechanisms of slope instability 
processes and sediment failures on continental margins: a geotechnical approach. Marine Geology 213, 291-321.

Sultan, N., Savoye, B., Jouet, G., Leynaud, D., Cochonat, P., Henry, P., Stegmann, S., Kopf, A.J., 2010. Investigation of a possible submarine landslide at the Var delta front (Nice continental slope, southeast France). Canadian geotechnical journal 47, 486-496.

Sultan, N., Voisset, M., Marsset, B., Marsset, T., Cauquil, E., Colliat, J.-L., 2007. Potential role of compressional structures in generating submarine slope failures in the Niger Delta. Marine Geology 237, 169-190.

Syvitski, J.P., 2007. Principles, methods and application of particle size analysis. Cambridge University Press, Cambridge.

Terzaghi, K., 1943. Theoretical soil mechanics. John Wiley \& Sons, New York.

Terzaghi, K., Peck, R., Mesri, G., 1996. Soil mechanics in engineering practice. John Wiley \& Sons, New York.

Vanneste, M., Longva, O., L'Heureux, J.-S., Vardy, M.E., Morgan, E., Forsberg, C.F., Kvalstad, T.J., Strout, J.M., Brendryen, J., Haflidasson, H., Lecomte, I., Steiner, A., Kopf, A.J., Mörz, T., Kreiter, S., 2013. Finneidfjord, a field laboratory for integrated submarine slope stability assessments and characterization of landslide-prone sediments: a review. Proceedings of the Offshore Technology Conference, Houston, Texas.

Vermeer, P., 1979. A modified initial strain method for plasticity problems, Proceedings of the Third International Conference on Numerical Methods in Geomechanics. Balkema, Rotterdam, pp. 377-387.

Wheeler, S.J., 1986. The stress-strain behaviour of soils containing gas bubbles. University of Oxford, Hilary. 
Yilmaz, Ö., 2001. Seismic data analysis: processing, inversion, and interpretation of seismic data. Society of Exploration Geophysicists, Tulsa. 


\section{Symbol list}

cpc Calypso piston core

CT one-dimensional compression test

$\mathrm{C}_{\mathrm{V}} \quad$ coefficient of consolidation

$\mathrm{d}_{1-3}$ regression in situ intact undrained shear strength at the seabed/surface

$\mathrm{d}_{\mathrm{dyn}}$ piezocone diameter of the dynamic-CPTU device

$\mathrm{d}_{\text {ref }}$ piezocone diameter of the static-CPTU device

E Young's modulus

Eref Young's modulus at seabed

$E_{\text {inc }}$ Young's modulus increase with depth

fc fall cone penetration

FoS factor of safety

$\mathrm{f}_{\mathrm{s}} \quad$ measured sleeve friction

$\mathrm{f}_{\mathrm{s}, \mathrm{dyn}} \quad$ dynamic measured sleeve friction

$\mathrm{f}_{\mathrm{s}, \mathrm{q}-\mathrm{s}} \quad$ strain-rate corrected (quasi-static) sleeve friction

$\mathrm{f}_{\mathrm{s}, \mathrm{ref}}$ measured sleeve friction recorded at the reference penetration rate i.e.

$2 \mathrm{~cm} / \mathrm{s}$

g gravity $\left(9.81 \mathrm{~m} / \mathrm{s}^{2}\right)$

gc gravity core

gsd grain size distribution

$\mathrm{H}_{\text {ini }}$ initial height of a specimen at the start of a loading increment

$\mathrm{I}_{\mathrm{L}} \quad$ liquidity index $\left(=\left(\omega-\omega_{\mathrm{P}}\right) /\left(\omega_{\mathrm{L}}-\omega_{\mathrm{P}}\right)\right)$

IP plasticity index $\left(=\omega_{\mathrm{L}}-\omega_{\mathrm{P}}\right)$

$\mathrm{k}_{1-3}$ regression in situ intact undrained shear strength gradient with depth

$\mathrm{k}_{\mathrm{f}} \quad$ coefficient of permeability

L1, L2, L3 3-layer system

MAD moisture and density 


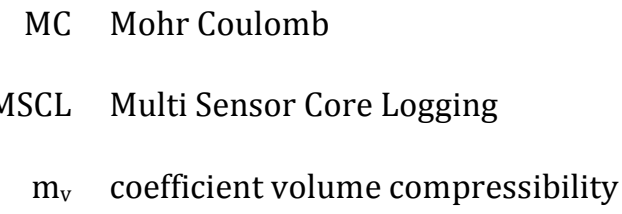

NAIL 1979 Nice airport landslide

$\mathrm{N}_{\mathrm{kt}}$ empirical cone resistance factor $\left(=\mathrm{q}_{\mathrm{net}} / \mathrm{s}_{\mathrm{u}}\right)$

PGA peak ground acceleration

$\mathrm{q}_{\mathrm{c}}$ measured cone penetration resistance

$\mathrm{q}_{\mathrm{t}}$ corrected cone penetration resistance

$\mathrm{q}_{\mathrm{t}, \mathrm{dyn}}$ dynamic corrected cone penetration resistance

$\mathrm{q}_{\mathrm{t}, \mathrm{q}-\mathrm{s}} \quad$ strain-rate corrected (quasi-static) cone penetration resistance

$\mathrm{q}_{\mathrm{t}, \mathrm{ref}}$ corrected cone penetration resistance recorded at the reference penetration rate i.e. $2 \mathrm{~cm} / \mathrm{s}$

SSC soil specific rate coefficient

$\mathrm{s}_{\mathrm{u}} \quad$ intact undrained shear strength

$\mathrm{S}_{\mathrm{u} \text {,ave }}$ average of triaxial and simple shear intact undrained shear strength

$\mathrm{S}_{\mathrm{u}, \mathrm{fc}} \quad$ intact fall cone penetration shear strength

$\mathrm{s}_{\mathrm{u}, \mathrm{qt}} \quad$ in situ intact undrained shear strength

$\mathrm{s}_{\mathrm{u}, \mathrm{reg}} \quad$ regression in situ undrained shear strength

$\mathrm{S}_{\mathrm{u}, \mathrm{v}-\mathrm{s}} \quad$ intact vane shear strength

u measured pore pressure

$\mathrm{u}_{2}$ measured pore pressure behind the tip

$\mathrm{V}_{\text {dyn }}$ dynamic penetration rate

$\mathrm{V}_{\mathrm{p}} \quad$ compressional wave velocity

$v_{\text {ref }}$ static penetration rate i.e. $2 \mathrm{~cm} / \mathrm{s}$

v-s vane shear

$\mathrm{V}_{\text {dyn }} \quad$ non-dimensional dynamic velocity

$\mathrm{V}_{\text {ref }}$ non-dimensional static velocity

WD water depth

z penetration depth; sediment depth 
$\gamma$ MSCL total unit weight

$\gamma_{\mathrm{t}}$ in situ total unit weight

$\gamma_{\mathrm{w}} \quad$ unit weight of water

$\Delta \mathrm{H}_{\mathrm{inc}}$ height difference of a specimen between start and end of a loading increment

$\Delta \sigma_{\text {inc }}$ effective stress difference related to the loading stage

$\Delta \mathrm{u} \quad$ excess pore pressure $\left(=\mathrm{u}-\mathrm{u}_{0}\right)$

$\Delta \mathrm{u}_{2} \quad$ excess pore pressure measured behind the tip $\left(=\mathrm{u}_{2}-\mathrm{u}_{0}\right)$

$\Delta \mathrm{u}_{2, \mathrm{dyn}} \quad$ dynamic excess pore pressure measured behind the tip

$\Delta \mathrm{u}_{2, \mathrm{q}-\mathrm{s}} \quad$ strain-rate corrected (quasi-static) excess pore pressure measured behind the tip

$\Delta \mathrm{u}_{2, \mathrm{ref}} \quad$ static excess pore pressure behind the tip recorded at the reference penetration rate i.e. $2 \mathrm{~cm} / \mathrm{s}$

$\alpha \quad$ slope angle

$\mu_{\mathrm{CPTU}, \mathrm{fs}} \quad$ soil specific rate coefficient for the measured sleeve friction

$\mu_{\mathrm{CPTU}, \mathrm{qt}}$ soil specific rate coefficient for the corrected cone penetration resistance

$\mu_{\mathrm{CPTU}, \Delta \mathrm{u}}$ soil specific rate coefficient for the excess pore pressure

$\rho$ MSCL gamma density

$\rho_{\mathrm{t}}$ in situ bulk density

$\sigma_{\mathrm{v} 0} \quad$ in situ total overburden stress

$\sigma_{\mathrm{v} 0}^{\prime} \quad$ in situ effective overburden stress

$v$ Poisson's ratio

$\omega$ moisture content

$\omega_{\mathrm{L}} \quad$ liquid limit

$\omega_{\mathrm{P}}$ plastic limit 


\section{Table Captions}

Table 1: Soil properties of clayey silt with embedded layers of sandy silt and sand derived from in situ CPTU tests, sedimentological and geotechnical experiments on cored samples taken from Calypso piston / gravity cores.

Table 2: List of selected surficial regression in situ intact undrained shear strength $\left(s_{u, r e g}\right)$ at the seabed $\left(d_{1}\right)$ and $s_{u, r e g}$ gradient $\left(k_{1}\right)$ with penetration depth.

Table 3: List of the shallow regression in situ intact undrained shear strength $\left(\mathrm{s}_{\mathrm{u}, \mathrm{reg}}\right)$ at the seabed $\left(\mathrm{d}_{2-3}\right)$ and $\mathrm{s}_{\mathrm{u}, \mathrm{reg}}$ gradient $\left(\mathrm{k}_{2-3}\right)$ with penetration depth.

Table 4: List of the regression in situ intact undrained shear strength $\left(\mathrm{s}_{\mathrm{u}, \mathrm{reg}}\right)$ at the seabed $\left(\mathrm{d}_{2}\right)$ and $\mathrm{s}_{\mathrm{u} \text {,reg }}$ gradient $\left(\mathrm{k}_{2}\right)$ with penetration depth collected at landslide eroded areas in the vicinity of the 1979 NAIL area. 


\section{Figure Captions}

Fig. 1: (a) Map of France (Europe) shows the city of Nice, which is located in the southeastern part of France. (b) Bathymetry image illustrates the upper slope and shelf morphology of the Ligurian margin. The 1979 Nice landslide area, airport and airport/harbor extension within the study area are also shown. The grid resolution of the bathymetry data is $15 \mathrm{~m}$. Dashed lines are projected traces of two prominent faults in the study area, the Blausasc fault (see Courboulex et al. 2007) and the Marcel fault (see Ai et al. 2014). (c) Overview map depicts the three main rivers located in the vicinity of Nice and the position of the Var stratigraphic and seismic reflection transects, presented in Figure 2.

Fig. 2: (a) The stratigraphic transect describes the detailed late Neogene-Quaternary sediment sequence of the Var river mouth modified after Dubar and Anthony (1995), Anthony and Julian (1997). (b) The seismic reflection transect illustrates well stratified as well as highly disturbed patterns for the Nice continental shelf and upper slope (modified after Kopf et al. 2008, 2009). The position of both transects is shown in Figure 1c.

Fig. 3: The bathymetry image shows the shelf and shelf break morphology off the Nice international airport, southeastern France, including the main part of the 1979 Nice landslide area and scar (dashed black line). The locations of all used dynamic penetrometer tests (circle), static penetrometer tests (box) and Calypso piston or gravity cores (pentagon) are pictured. The black lines indicate the 2D chirp seismic and numerical slope stability transects shown in Figures 8a, 8b, 14a, 14b and 14c. The dashed white contour lines depict the morphology with a depth interval of $25 \mathrm{~m}$, while the grey linear shading outlines the area where free gas is observed. 
Fig. 4: (a) The Ifremer Penfeld penetrometer is shown including a rough description of the main components of this seabed tool (see also Meunier et al. 2000 and 2004 for details). A general drawing of the hydrostatic pressure compensated multisensor piezocone cone is also illustrated (copyright Ifremer). (b) The MARUM shallow-water dynamic penetrometer is presented including a picture of the main electronic (see also Stegmann et al. 2006, Steiner et al. 2012 for details). The measured cone penetration resistance $\left(\mathrm{q}_{\mathrm{c}}\right)$, measured sleeve friction $\left(\mathrm{f}_{\mathrm{s}}\right)$ and measured pore pressure behind the tip $\left(\mathrm{u}_{2}\right)$ are dynamic parameters according to the strain-rate effect (see section 4.1.1) (copyright MARUM).

Fig. 5: Data protocol from dynamic CPT deployment 23-st offshore Nice airport, showing (a) acceleration and penetration velocity, (b) tip resistance $\mathrm{q}_{t}$ and (c) sleeve friction $\mathrm{f}_{\mathrm{s}}$ vs. depth. Panel c further shows quasi-static Penfeld CPT data at site 11-s6 from Sultan et al. (2010) for comparison. For location, see Fig. 3.

Fig. 6: Sedimentological and geotechnical profile of the gravity core 919-gc collected at the shelf break off the Nice international airport (southeastern France). (a) The visual core description is shown. (b) The laboratory geotechnical profiles comprise the intact vane shear strength $\left(\mathrm{s}_{\mathrm{u}, \mathrm{v}-\mathrm{s}}\right)$, intact fall cone penetration strength $\left(\mathrm{s}_{\mathrm{u}, \mathrm{fc}}\right)$ measured on 919gc (box and circle) and the first $4 \mathrm{~m} \mathrm{~s}_{\mathrm{u}, \mathrm{v}-\mathrm{s}}$ of the Calypso piston core 2470-cpc (grey corridor; Sultan et al. 2004). In addition to the laboratory datasets, two adjacent dynamic-CPTU profiles, labeled by 13-st and 954-3, are depicted using an empirical cone penetration resistance factor $\left(\mathrm{N}_{\mathrm{kt}}\right)$ of 20 to derive the in situ intact undrained shear strength $\left(\mathrm{s}_{\mathrm{u}, \mathrm{qt}}\right)$ from the corrected cone penetration resistance $\left(\mathrm{q}_{\mathrm{t}}\right)$. (c) The quasi-static excess pore pressure profiles $\left(\Delta \mathrm{u}_{2, \mathrm{q}-\mathrm{s}}\right)$ of 13 -st, $954-3$ and 14-st are illustrated. The first two are potentially influenced by free gas growth, while the latter is unaffected and located in an eroded area (see Fig. 3 for location). 
Fig. 7: The cumulative grain size distribution is shown according to ISO 14688-1 (2002). Grain size is subdivided in three sections representing the main sediment classes of the study area, described as clayey silt, sandy silt and silty sand - sand.

Fig. 8: (a) 2D chirp seismic transect (ha100) located south to the center part of the shelf, and (b) the second transect (ha102) located at the western part of the shelf and shelf break are shown (see Fig. 3 for locations). Both transects contain the positions of the in situ and coring profiles, and illustrate the coarse-grained beds (dashed black line) and weak zone (shaded area). The morphological scars, landslide eroded areas and morphological steps are also marked. (c, d) The in situ intact undrained shear strength $\left(\mathrm{s}_{\mathrm{u}, \mathrm{q}}\right)$ profiles of crucial tests are illustrated using an empirical cone penetration resistance factor $\left(\mathrm{N}_{\mathrm{kt}}\right)$ of 20 . The $\mathrm{s}_{\mathrm{u}, \mathrm{qt}}$ drop and $\mathrm{s}_{\mathrm{u}, \mathrm{qt}}$ minimum related to the weak zone can be seen.

Fig. 9: The in situ intact undrained shear strength $\left(\mathrm{s}_{\mathrm{u}, \mathrm{qt}}\right)$ of the static-CPTU test 12 -s 3 (modified after Leynaud and Sultan 2010) and the intact vane shear strength of the 2470-cpc (after Sultan et al. 2004) are illustrated considering a empirical cone penetration resistance factor $\left(\mathrm{N}_{\mathrm{kt}}\right)$ of 20 . The regression range for the static-CPTU tests (grey corridor) and regression line for 2470-cpc (dashed black line) are shown and supplemented by the surficial $\left(\mathrm{k}_{1}, \mathrm{~d}_{1}\right)$ and shallow $\left(\mathrm{k}_{2-3}, \mathrm{~d}_{2-3}\right)$ average regression parameters. The $\mathrm{s}_{\mathrm{u}, \mathrm{qt}}$ drop and $\mathrm{s}_{\mathrm{u}, \mathrm{qt}}$ minimum related to the weak zone are also depicted and quantified.

Fig. 10: Example of a dynamic-CPTU profile (23-st) showing the in situ intact undrained shear strength $\left(\mathrm{s}_{\mathrm{u}, \mathrm{q}}\right)$ derived from the corrected cone penetration resistance $\left(\mathrm{q}_{\mathrm{t}}\right)$ and the associated regression in situ intact undrained shear strength $\left(\mathrm{s}_{\mathrm{u}, \mathrm{reg}}\right)$. The empirical cone penetration resistance factor $\left(\mathrm{N}_{\mathrm{kt}}\right)$ is 20 . The regression equation, $\mathrm{s}_{\mathrm{u}, \text { reg }}$ at the seabed $\left(\mathrm{d}_{1}\right)$ and $\mathrm{s}_{\mathrm{u}, \mathrm{reg}}$ gradient $\left(\mathrm{k}_{1}\right)$ with penetration depth $(\mathrm{z})$ are illustrated and quantified. The soft, stiff and probably coarse-grained beds are marked. 
Fig. 11: (a) Area-wide contour map of the regression in situ intact undrained shear strength $\left(\mathrm{s}_{\mathrm{u}, \mathrm{reg}}\right)$ at the seabed, bathymetrical image and contour map with a depth interval of $25 \mathrm{~m}$ (dashed white lines), and several dynamic-CPTU benchmarks and associated parameters are illustrated. The dashed black line depicts the 1979 Nice landslide scar. (b) Area-wide contour map of the regression in situ intact undrained shear strength $\left(\mathrm{s}_{\mathrm{u}, \mathrm{reg}}\right)$ gradient with penetration depth, bathymetrical picture and contour map with a depth interval of $25 \mathrm{~m}$ (dashed white lines), and several dynamicCPTU benchmarks and related values are shown. The dashed black line depicts the 1979 Nice landslide scar.

Fig. 12: In situ total unit weight $\left(\gamma_{\mathrm{t}}\right)$ profiles, derived from dynamic- and static-CPTU tests using the empirical solution proposed by Mayne et al. (2010), are shown (see also Eq. 5). In addition, laboratory total unit weight records based on consolidation tests (after Dan et al. 2007) and MCSL logging (see also Leynaud and Sultan 2010) are illustrated.

Fig. 13: Geometrical boundaries, in situ total unit weight $\left(\gamma_{t}\right)$ and regression in situ intact undrained shear strength $\left(\mathrm{d}_{1-3}, \mathrm{k}_{1-3}\right)$ distributions of two 2D finite element models are illustrated. The 2D finite element models are located at the chirp transects ha100 (a) and ha102 (b). A sketch of the implemented strength profile with penetration depth is also depicted including the reference to the 3-layer system (L1, L2, L3).

Fig. 14: Results of the 2D numerical slope stability analyses presenting the initial and overall shear failure geometries and failure depths for the transects ha100 (a) and ha102 (b, c). 

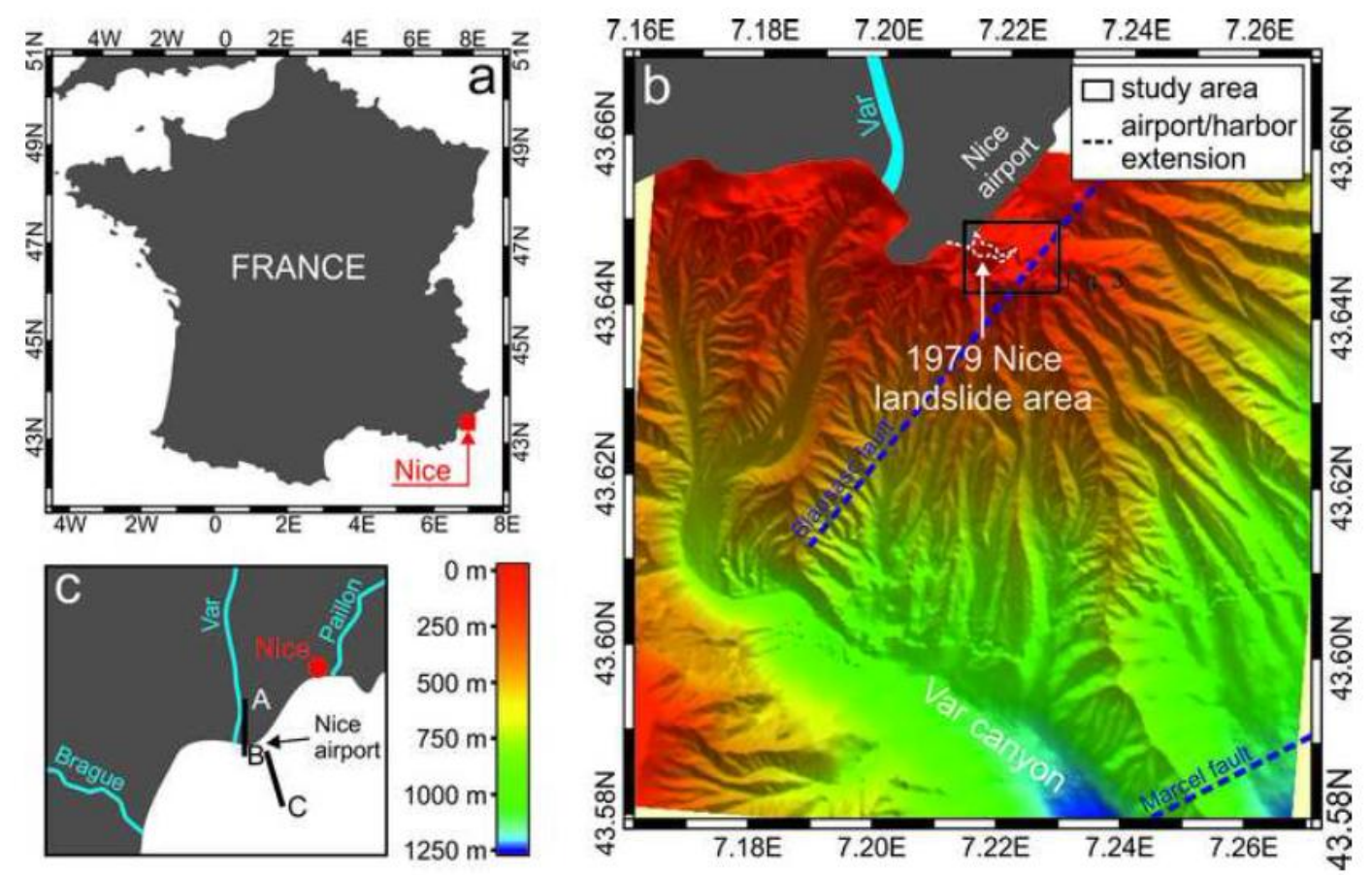

Fig. 1

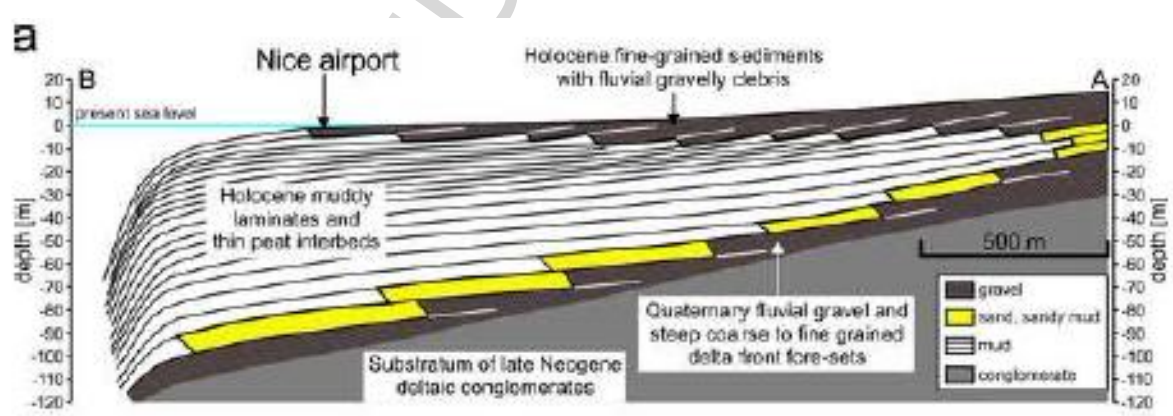

b

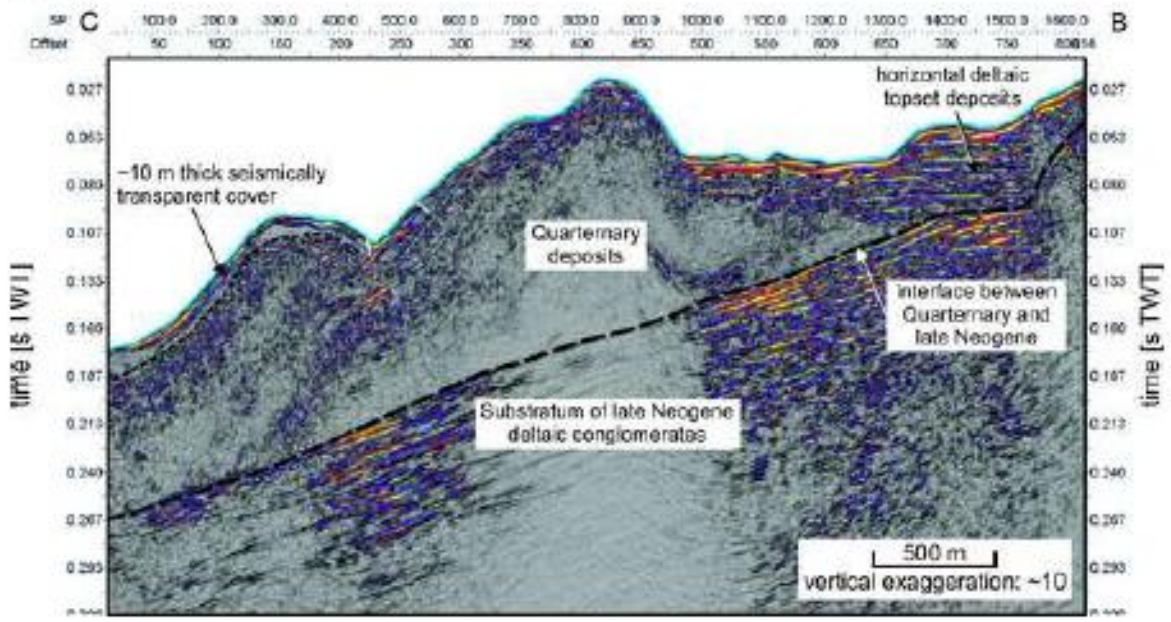

Fig. 2 


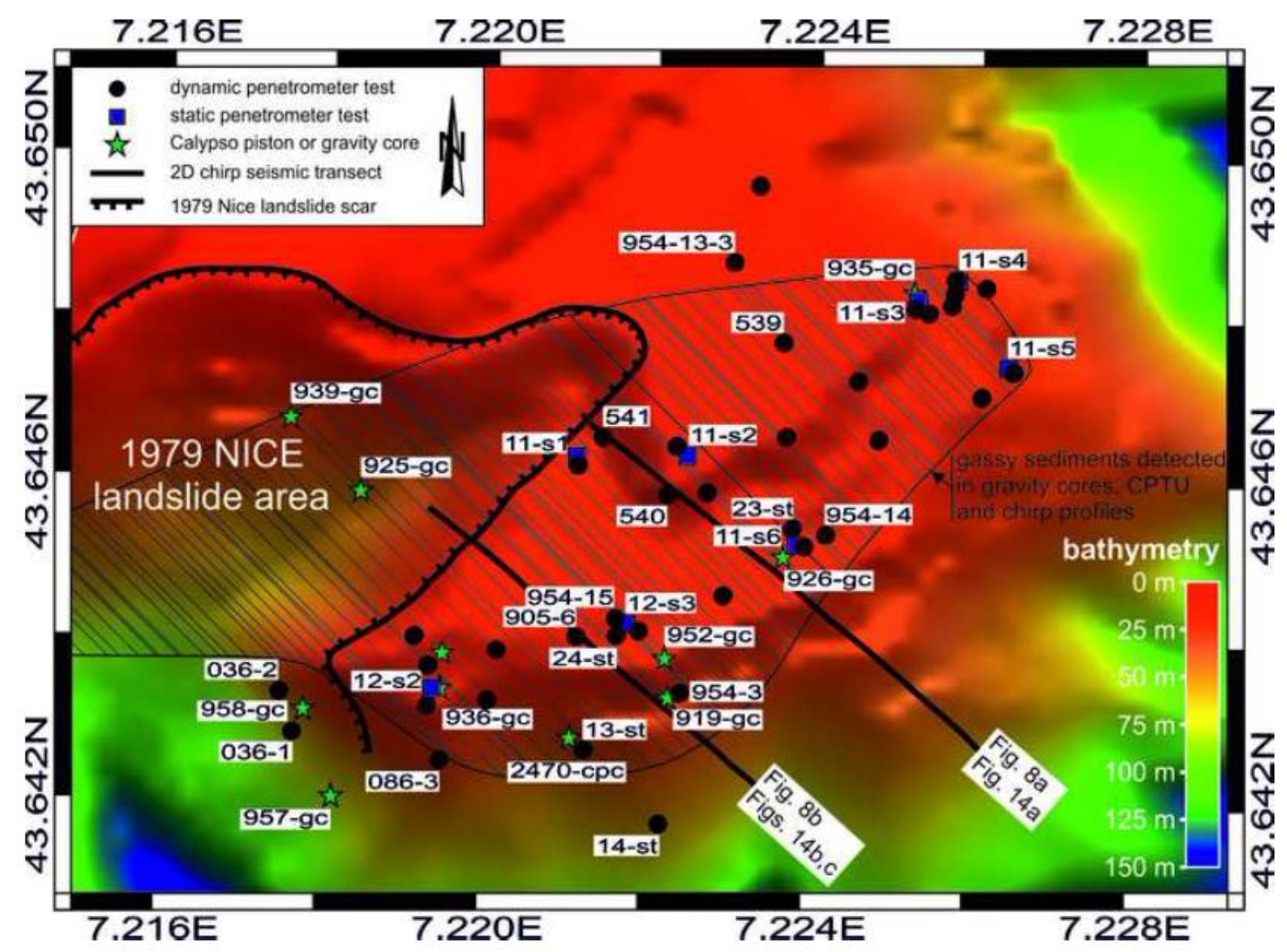

Fig. 3
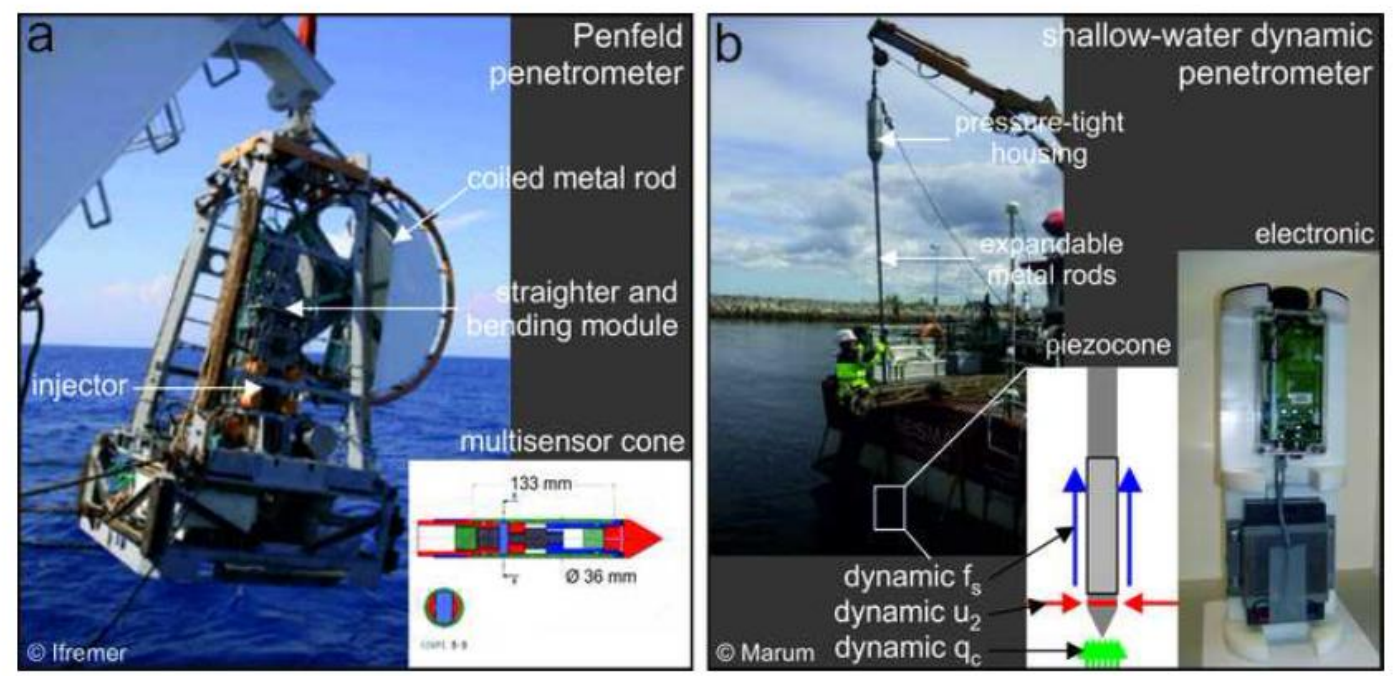

Fig. 4 

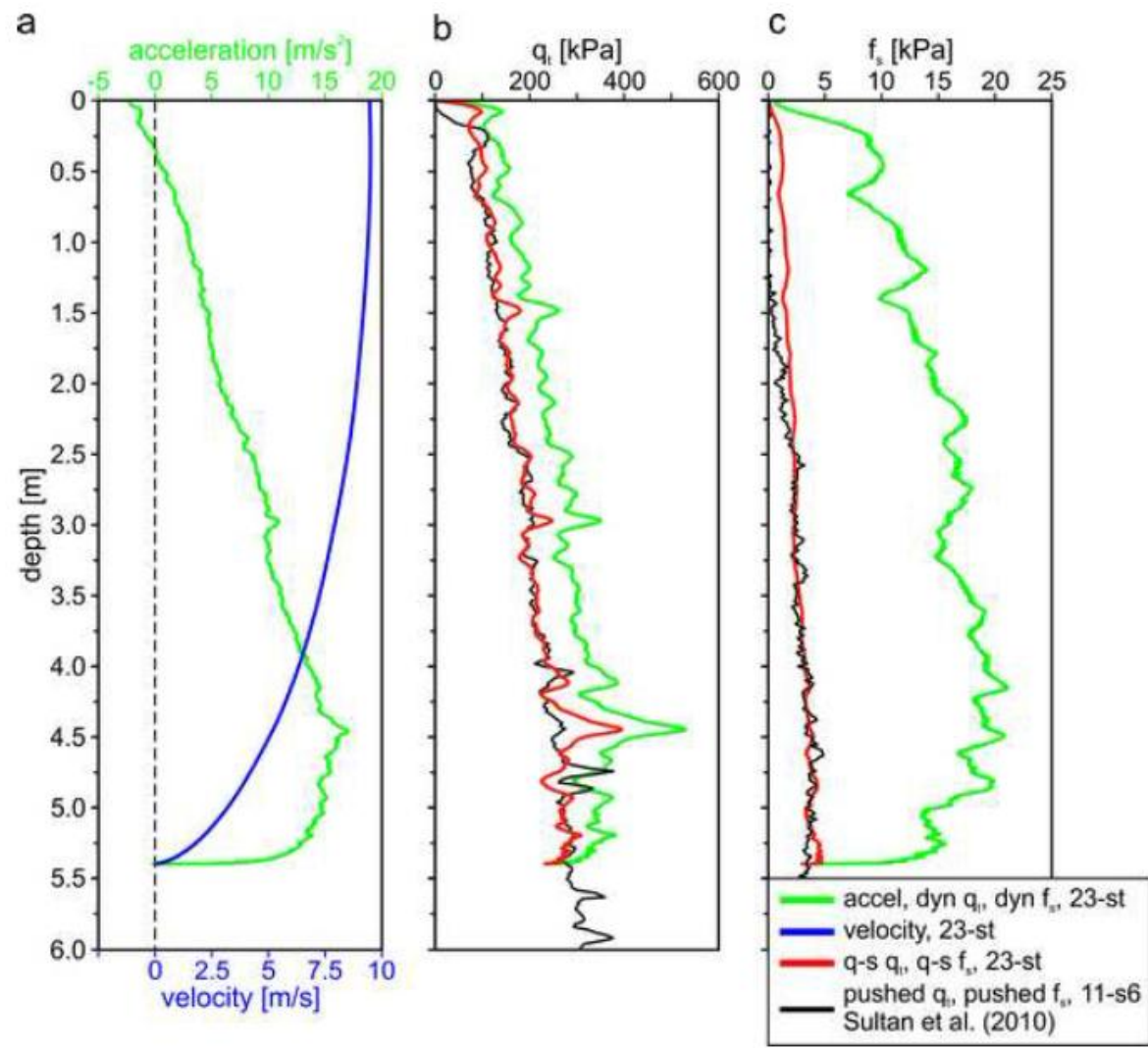

Fig. 5 


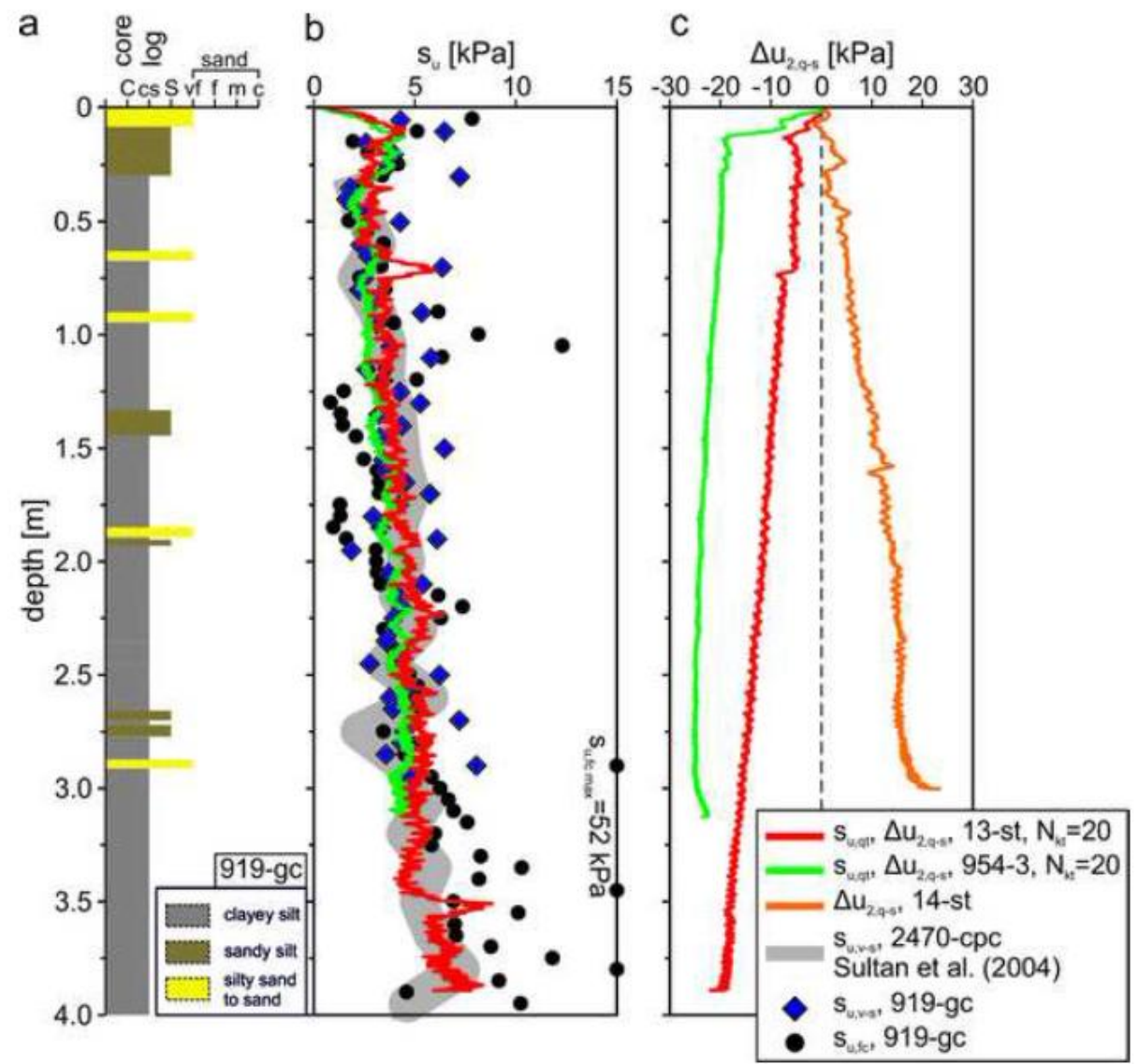

Fig. 6 


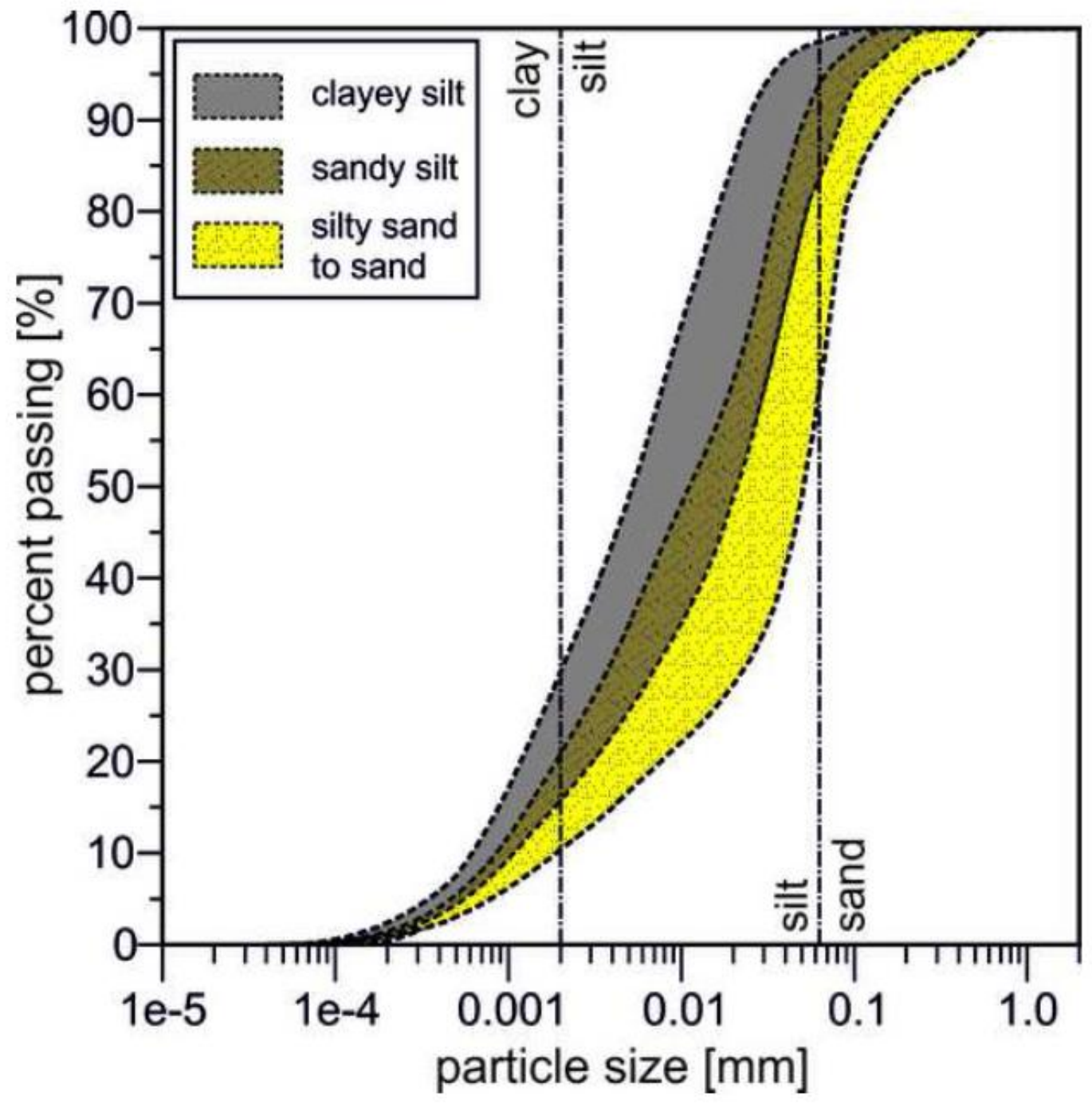

Fig. 7 


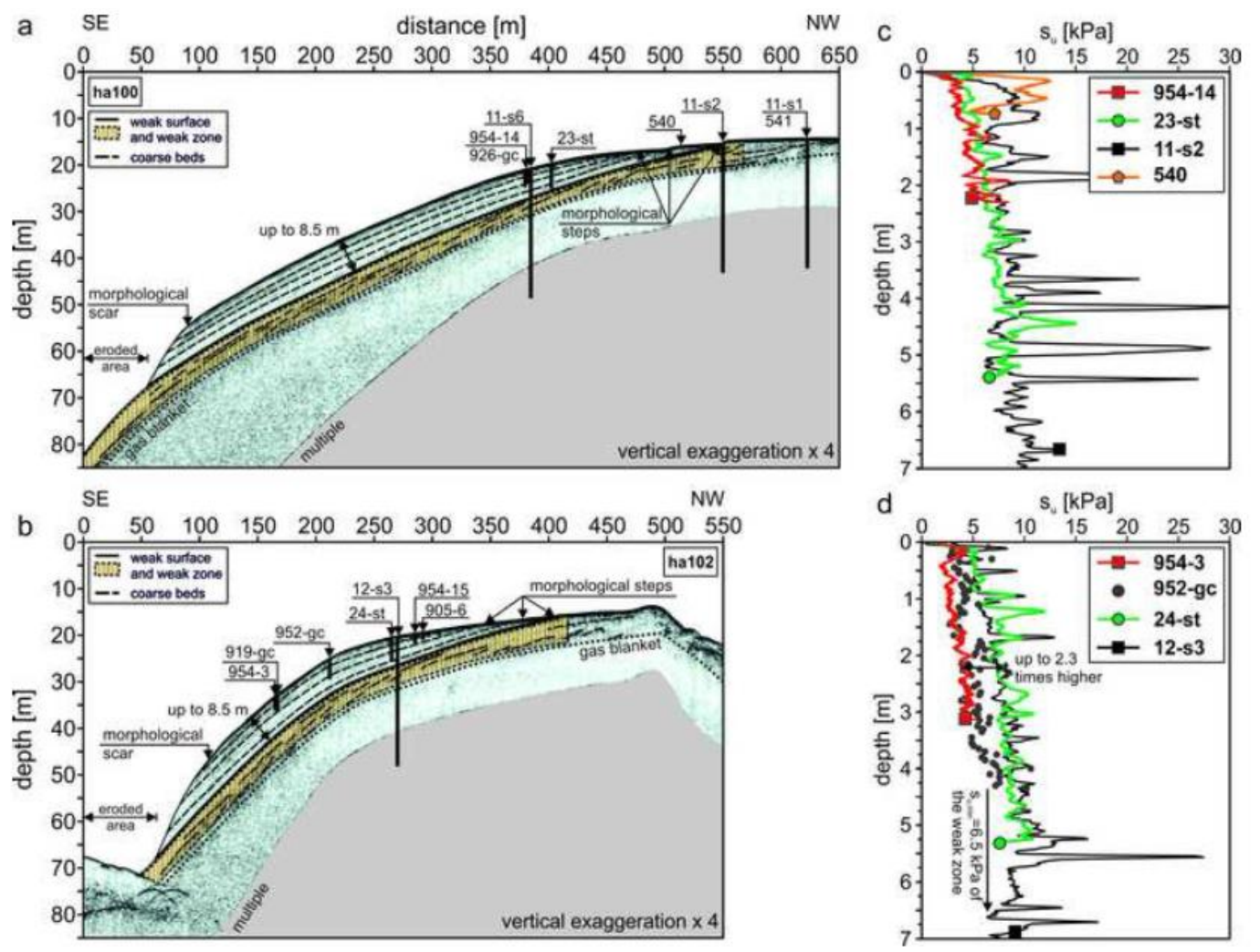

Fig. 8 


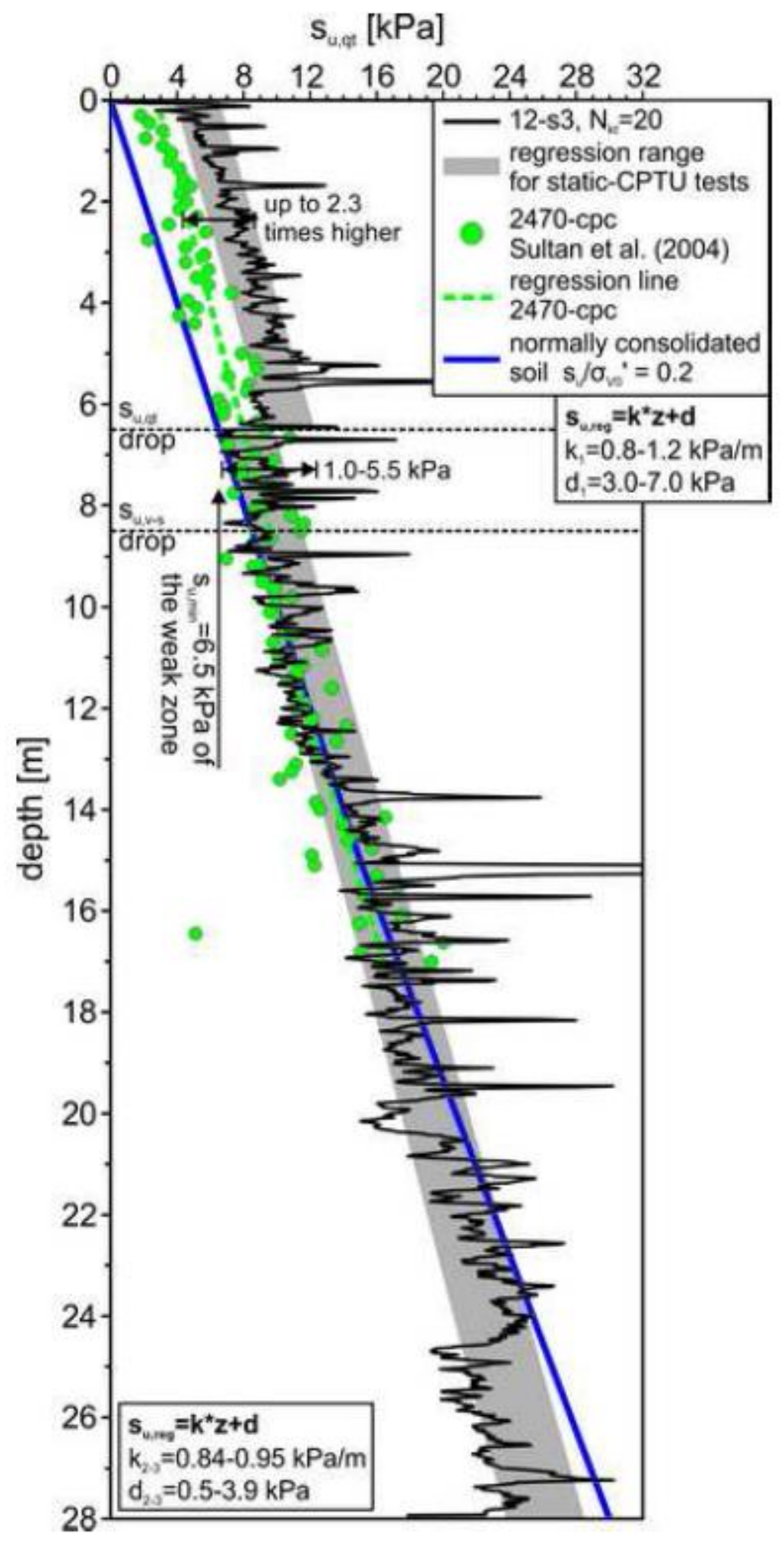

Fig. 9 


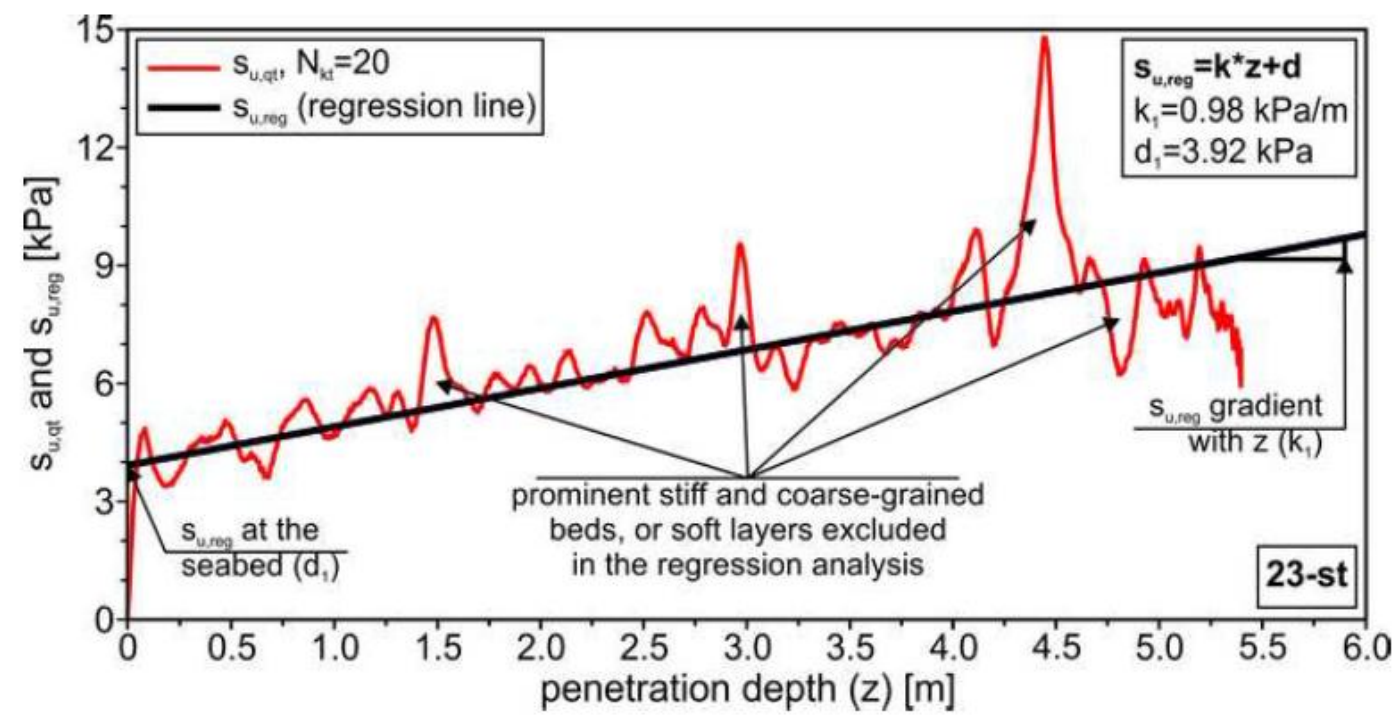

Fig. 10 

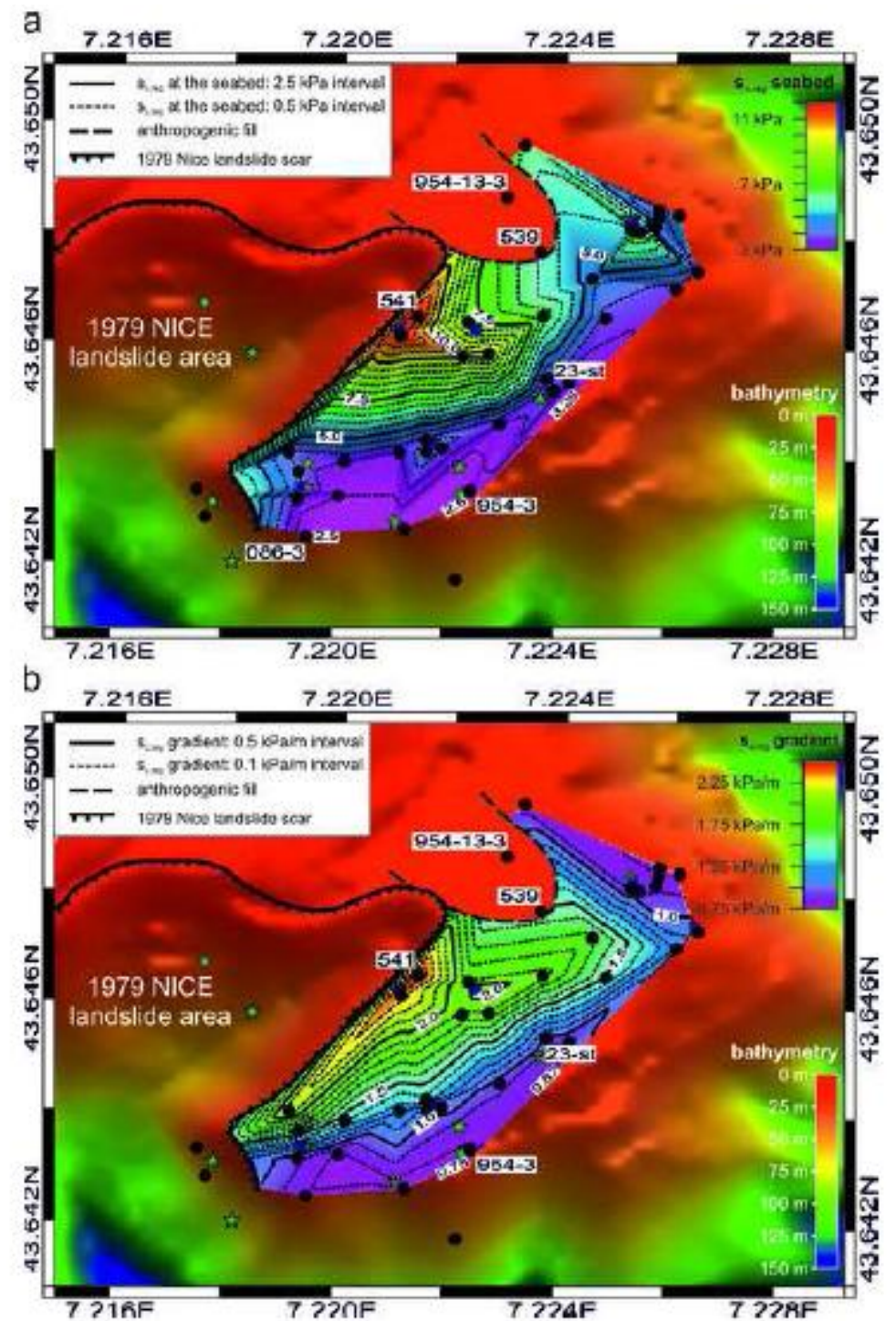

Fig. 11 


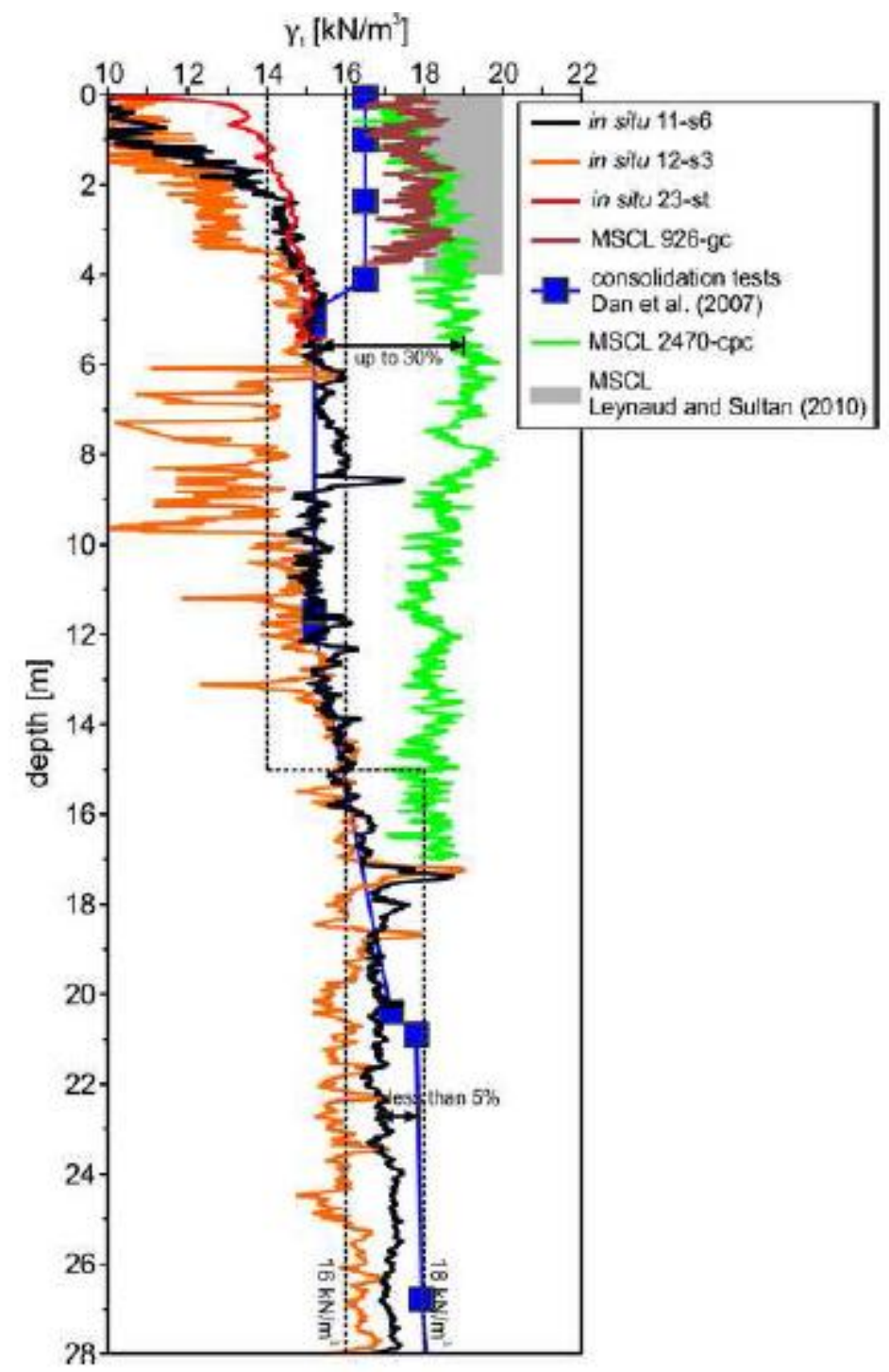

Fig. 12 
a distance $[\mathrm{m}]$
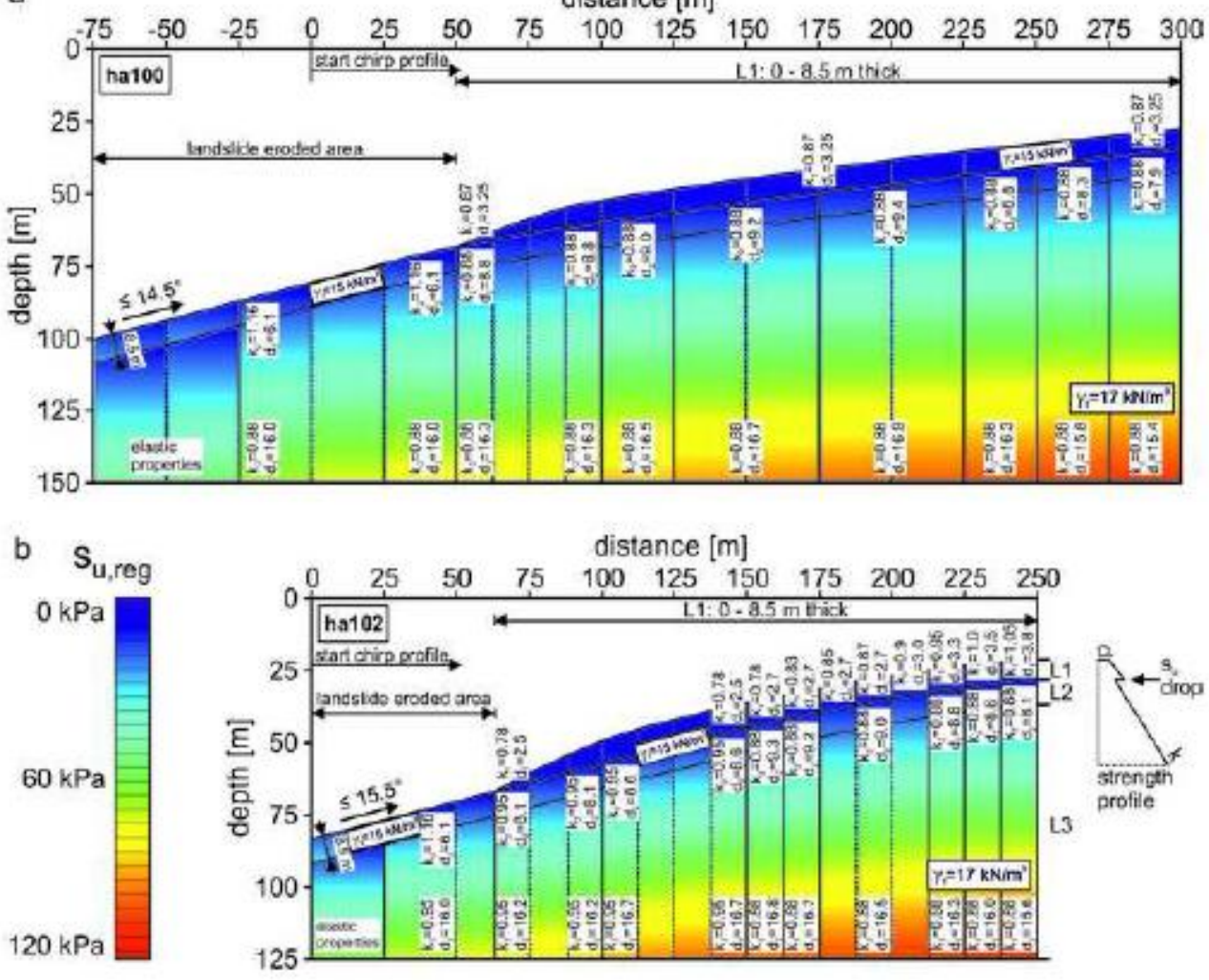

Fig. 13

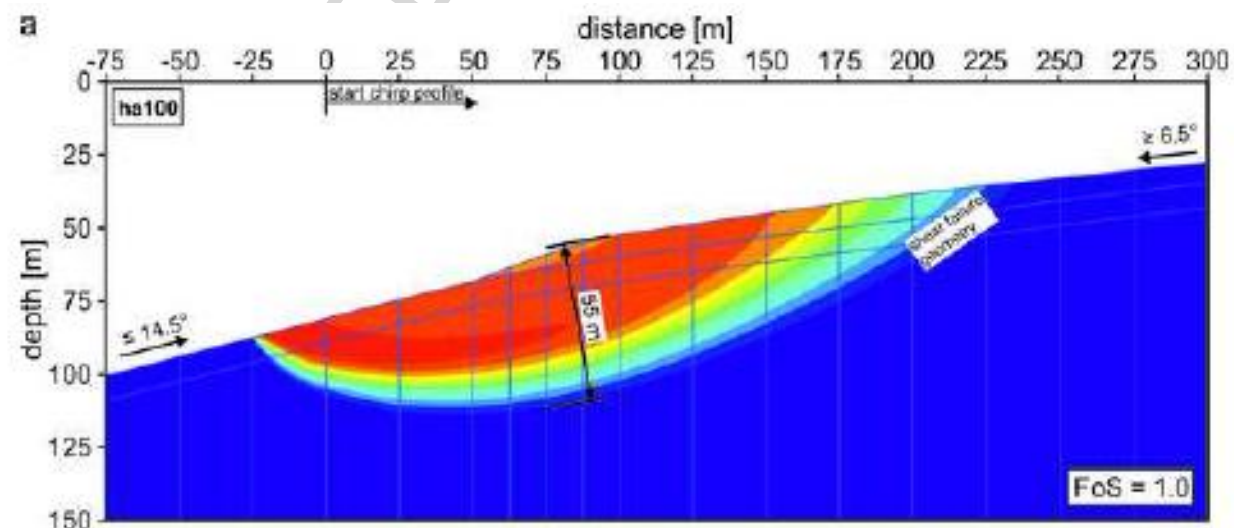

b

distance [m]
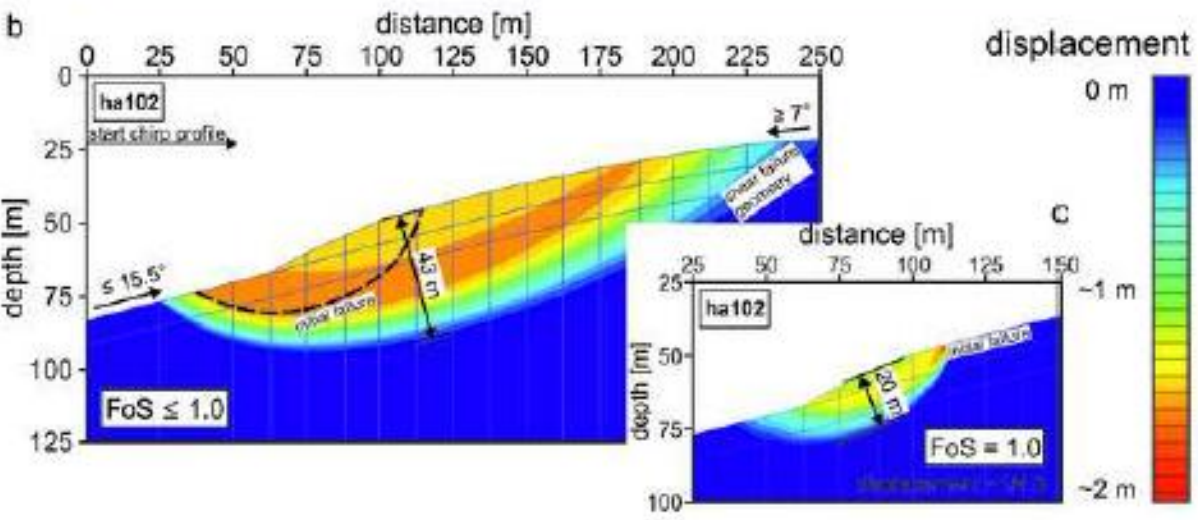

Fig. 14 


\section{Table 1}

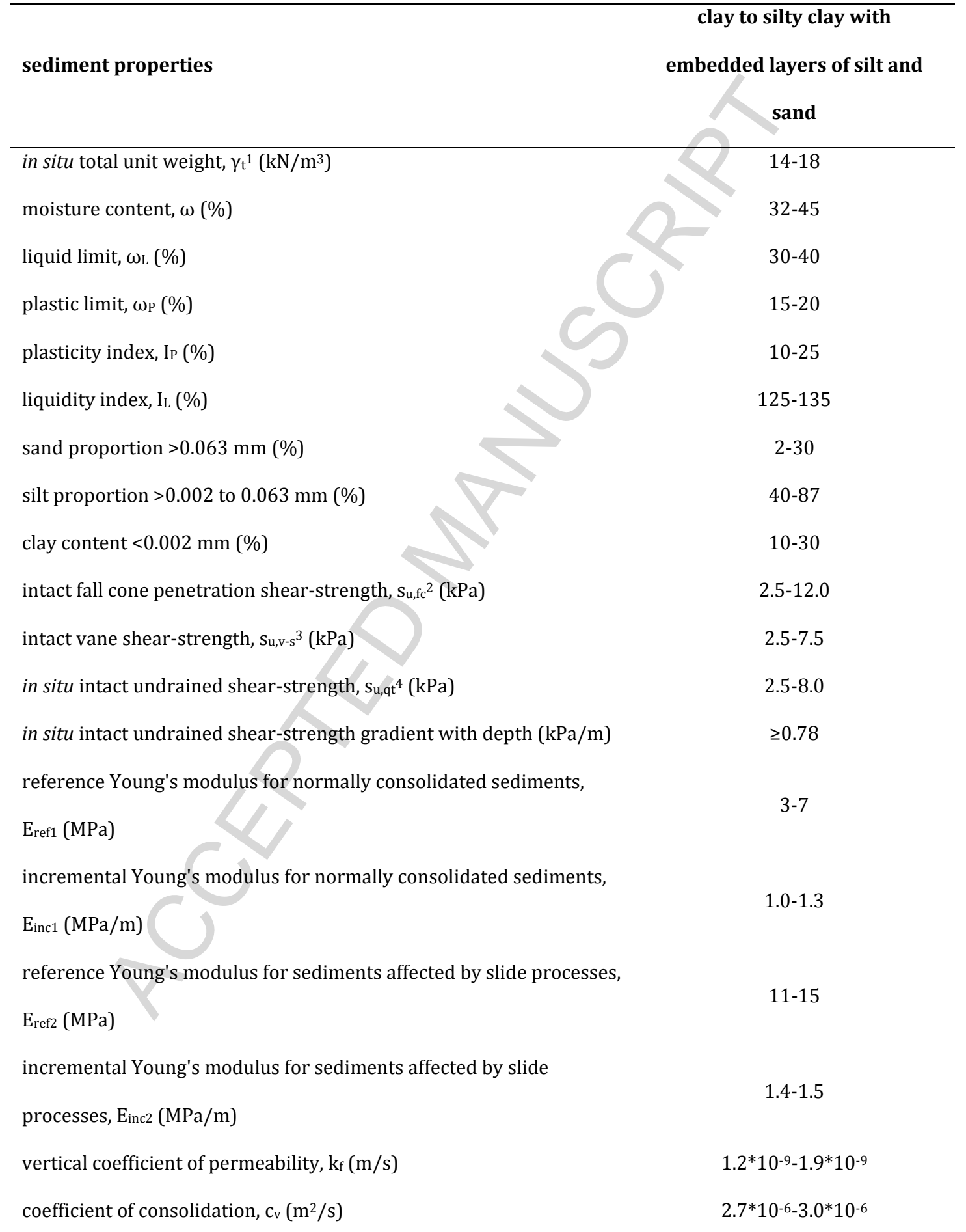

Note: $\quad 1$ derived in situ parameters based on Mayne et al. (2010), $2 \mathrm{fc}=$ fall cone penetration experiment, post cruise, ${ }^{3} \mathrm{v}$-s = vane shear experiment, post cruise, and ${ }^{4}$ in situ intact undrained shear-strength derived from the corrected cone penetration resistance. 


\section{Table 2}

\begin{tabular}{|c|c|c|}
\hline \multirow{2}{*}{ in situ and coring data } & \multicolumn{2}{|c|}{ surficial regression in situ intact undrained shear-strength } \\
\hline & $\mathbf{k}_{1}(\mathrm{kPa} / \mathrm{m})$ & $\mathrm{d}_{1}(\mathrm{kPa})$ \\
\hline 086-3 & 0.80 & 2.49 \\
\hline 11-s1 & 2.45 & 11.25 \\
\hline $11-\mathrm{s} 2$ & 2.08 & 7.78 \\
\hline 11 -s6 & 0.92 & 4.26 \\
\hline $12-\mathrm{s} 3$ & 1.14 & 4.44 \\
\hline 23-st & 0.98 & 3.92 \\
\hline 24-st & 1.03 & 4.58 \\
\hline 539 & 173.10 & 43.28 \\
\hline 540 & 1.87 & 10.14 \\
\hline 541 & 2.52 & 11.70 \\
\hline $905-6$ & 1.22 & 3.47 \\
\hline 919-gc & 0.78 & 2.70 \\
\hline 926-gc & 0.89 & 3.64 \\
\hline $952-\mathrm{gc}$ & 0.87 & 2.68 \\
\hline $954-3$ & 0.78 & 2.49 \\
\hline 954-13-3 & 219.90 & 40.86 \\
\hline $954-14$ & 0.87 & 3.25 \\
\hline 954-15 & 1.37 & 3.82 \\
\hline
\end{tabular}




\section{Table 3}

\begin{tabular}{|c|c|c|}
\hline \multirow{2}{*}{ in situ and coring data } & \multicolumn{2}{|c|}{ shallow regression in situ intact undrained shear-strength } \\
\hline & $\mathrm{k}_{2-3}(\mathrm{kPa} / \mathrm{m})$ & $\mathrm{d}_{2-3}(\mathrm{kPa})$ \\
\hline 11-s3 & 0.89 & 3.89 \\
\hline $11-\mathrm{s} 4$ & 0.84 & 1.60 \\
\hline $11-\mathrm{s} 5$ & 0.87 & 1.81 \\
\hline $11-\mathrm{s} 6$ & 0.87 & 0.65 \\
\hline 12 -s2 & 0.89 & 2.14 \\
\hline 12 -s3 & 0.90 & 1.61 \\
\hline $2470-$ срс & 0.95 & 0.52 \\
\hline
\end{tabular}




\section{Table 4}

regression in situ intact undrained shear-strength for the

in situ and coring data

landslide eroded areas

\begin{tabular}{ccc} 
& & \\
\cline { 2 - 3 } & $\left.\mathbf{k}_{2} \mathbf{( k P a} / \mathbf{m}\right)$ & $\mathbf{d}_{2}(\mathbf{k P a})$ \\
\hline $036-1$ & 1.13 & 6.90 \\
$036-2$ & 1.20 & 6.90 \\
$14-\mathrm{st}$ & 1.15 & 3.71 \\
$958-\mathrm{gc}$ & 1.17 & 6.98 \\
\hline
\end{tabular}

